\title{
3 Key Questions about Phenotypic Plasticity
}

\author{
David W. Pfennig \\ University of North Carolina
}

\section{CONTENTS}

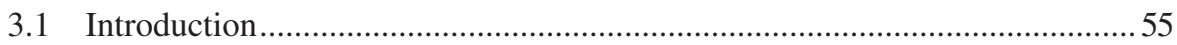

3.2 Question 1: Does Plasticity Confer a Unique Evolutionary Advantage?.........58

3.3 Question 2: What Are the Proximate Mechanisms of Plasticity? .....................60

3.4 Question 3: When Should Plasticity Evolve, and What Form Should

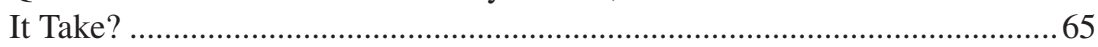

3.5 Question 4: Can Plasticity Influence Evolution? ........................................... 74

3.6 Question 5: Does Plasticity Fit within Existing Evolutionary Theory? ...........78

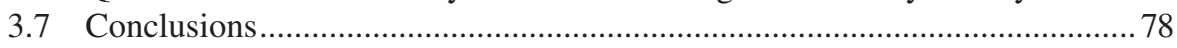

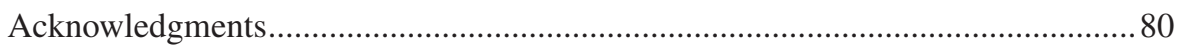

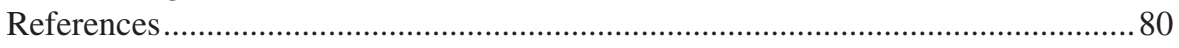

\subsection{INTRODUCTION}

Phenotypic plasticity - the ability of an individual organism to change its phenotype in direct response to variation in its environment-has long fascinated and perplexed biologists. Indeed, its widespread existence demands that we confront such vexing questions as: Are an organism's features determined solely by its genome, or does its environment also play a role? Can environmentally induced features be passed on to the individual's offspring? And, does plasticity impact evolution? Many biologists would likely respond to these questions by arguing that an organism's genes are the primary cause of variation and the exclusive cause of inheritance and that plasticity therefore cannot influence evolution. So pervasive is this perspective that it has permeated much of science and has even become entrenched in the public psyche. Consider, for instance, the following statement from one of the world's leading biological research organizations:

Each genome contains all of the information needed to build and maintain that organism.

U. S. National Institutes of Health (2020)

Yet, an increasing number of scientists have begun questioning these fundamental precepts that minimize the environment's role in development and evolution. Behind this change in perspective is a growing realization that phenotypes emerge from 
the interplay of genes and environmental factors; that a change in an individual's environment can generate pronounced trait variation through plasticity (Figure 3.1); that, under certain circumstances, some such environmentally modified traits can be passed on to offspring; and that plasticity might influence evolution and leave an indelible imprint on the history of life. Indeed, although phenotypic plasticity is increasingly appreciated for its practical applications (Box 3.1), it remains especially controversial in evolutionary biology.

In this chapter, I explore these issues by examining five key questions about phenotypic plasticity. These questions are: (1) Does plasticity confer a unique evolutionary advantage? (2) What are the proximate mechanisms of plasticity? (3) When should plasticity evolve, and what form should it take? (4) Can plasticity

(a)

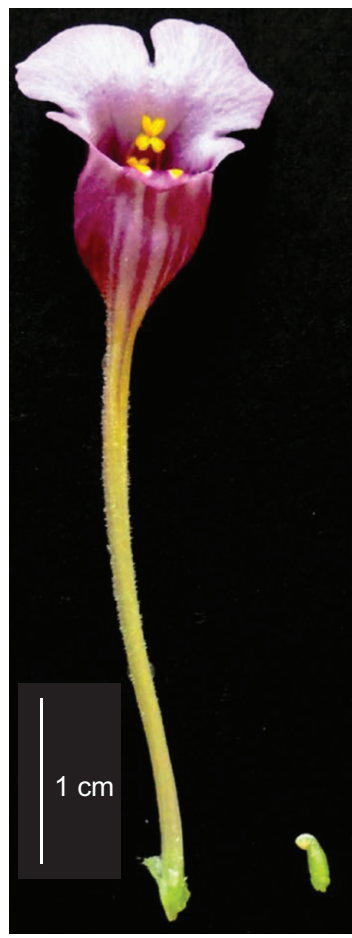

(b)
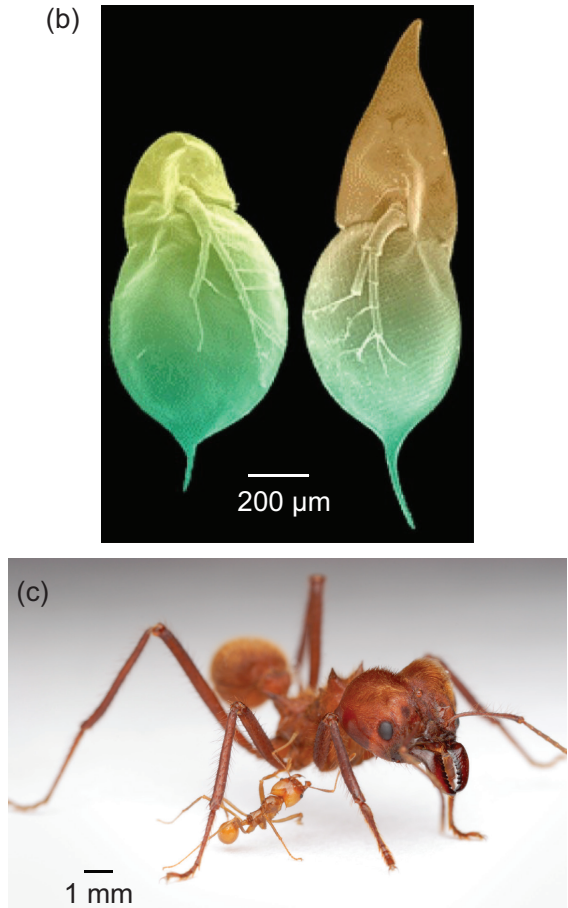

FIGURE 3.1 Spectacular examples of phenotypic plasticity occur in organisms that display 'polyphenism,' in which multiple, discrete phenotypes arise from a single genotype as a result of differing environmental conditions. For instance, (a) monkeyflower plants (Mimulus douglasii) produce large open ('chasmogamous') flowers (left) or, in response to longer day lengths, small closed ('cleistogamous') flowers (right); (b) a single clone of water fleas (Daphnia cucullata) can produce either a normal morph (left) or, in the presence of predators, a helmeted morph (right); and (c) depending on the nutrition they receive as larvae, leafcutter ants (Atta cephalotes) develop into either a large major worker or a small minor worker. Based on: (a) Barnett et al. (2018); (b) Agrawal et al. (1999); (c) Wheeler (1986). (Photos reproduced with the kind permission of: [a] Laryssa Barnett; [b] Christian Laforsch and Ralph Tollrian; [c] Alex Wild.) 
influence evolution? and (5) Does plasticity fit within existing evolutionary theory? Of course, these five questions do not constitute all of the interesting questions one could possibly ask about plasticity. Instead, this list is intended to provide an overview of what we know-and what we do not know-about the causes and consequences of plasticity, especially as they pertain to evolution. Moreover, these questions will set the stage for the remainder of the book, where they will be considered in greater detail. After discussing the five questions, I conclude with suggestions for future research.

\section{BOX 3.1 SOME PRACTICAL APPLICATIONS OF PLASTICITY}

- Predicting evolutionary responses to climate change. The capacity of individual organisms to display plasticity, coupled with the capacity of populations to undergo adaptation, will likely determine which species will 'win' and which will 'lose' under anthropogenic environmental change (Diamond and Martin 2016).

- Optimizing agricultural yields. Understanding plasticity is important for knowing how to reduce its effects. For example, in developing crops, it is essential to reduce plasticity to ensure that the same crop produces high yields in different parts of the world, despite differences in environment. Fisheries and animal husbandry could similarly benefit from understanding how to select on phenotypic plasticity (de Jong and Bijma 2002).

- Understanding the causes of nonheritable birth defects (teratogens) in both humans and nonhuman animals. The environment is a font of information for normal development; however, it can also disrupt development. Indeed, $2 \%-5 \%$ of human infants are born with an anatomical abnormality, as are an increasing number of other animals. Although some abnormalities have genetic causes, many are triggered by environmental factors (Gilbert and Epel 2015).

- Clarifying the evolutionary causes of nutrition-related disease in humans. Nutrition-induced plasticity is common in humans (Gluckman et al. 2009), and it can lead to obesity and obesity-related diseases (Bateson et al. 2004). For example, obesity affects more than $300,000,000$ people worldwide. The most dangerous form is exaggerated development of visceral adipose tissue (VAT). It has recently been proposed that selection favored increased investment in VAT among individuals that were food deprived when young as adaptive anticipatory plasticity to mitigate malnourishment in adulthood (West-Eberhard 2019).

- Understanding the human brain. In response to changes in the environment, brains can 're-wire' synaptic interactions. Such 'neuroplasticity' can even allow neurons to compensate for injury and disease (Shaw et al. 2001). 


\subsection{QUESTION 1: DOES PLASTICITY CONFER A UNIQUE EVOLUTIONARY ADVANTAGE?}

Phenotypic plasticity is ubiquitous (Nijhout 2003; Palacio-López et al. 2015). Indeed, when confronted with environmental variation, all organisms can modify some aspect of their phenotype or adjust their internal conditions to maintain a stable equilibrium (Whitman and Agrawal 2009; Gilbert and Epel 2015; Sultan 2015). These adjustments range from conspicuous changes in morphology (Figure 3.1) to subtle changes in gene expression, which are generally invisible to an outside observer but which are found across all taxa. Thus, there is no such thing as a non-plastic organism. Plasticity can therefore be viewed as a defining feature of life (Nijhout 2003).

But why is plasticity ubiquitous? One obvious answer is that plasticity confers a unique evolutionary advantage. Although some forms of plasticity arise as an unavoidable consequence of fundamental laws of chemistry or physics and are therefore not necessarily beneficial (for instance, poor nutrition leads to stunted growth in most organisms, which is generally not beneficial; Monaghan 2008), many forms increase the bearer's fitness. For example, when attacked by herbivores, certain plants greatly increase the production of defense chemicals (glucosinolates) in their leaves, which deters further attacks (War et al. 2012). Similarly, predation is reduced following predator-induced increases in body length in Daphnia (Agrawal et al. 1999; see Figure 3.1b) and shell thickness in snails (Auld and Relyea 2011). More generally, numerous studies have shown that plasticity can be adaptive (for examples, see Watt 1968; Pfennig 1990; Warkentin 1995; Van Buskirk et al. 1997; Denver et al. 1998; Wells and Pigliucci 2000; Kishida and Nishimura 2004; Lyytinen et al. 2004), although not necessarily for all traits or all environmental conditions that the organism might encounter (Caruso et al. 2006; Auld and Relyea 2011). Why is plasticity often beneficial? Here, I describe how plasticity bestows on its bearer a unique evolutionary advantage: it provides a mechanism whereby an individual organism can modify its phenotype to match its current environment, including rapidly changing and even novel environments.

Consider that every natural environment varies, whether spatially or temporally, and whether owing to abiotic factors, such as climate, or biotic factors, such as predation. Moreover, these fluctuations often occur within the lifetimes of individual organisms (Levins 1968). Such changing environmental conditions can be harmful because they erode the match between the organism's phenotype and its environment (Levins 1968). Although adaptive evolution can help maintain this match (Meyers and Bull 2002), evolution can only occur (by definition) between generations. Consequently, adaptive evolution is always one (or more) generation(s) behind in responding to environmental variation. Even rapid evolution (Reznick et al. 2019) cannot keep pace with environmental change that occurs more rapidly than an organism's generation time.

Plasticity, by contrast, generates phenotypic change within generations. Plasticity can therefore potentially keep up with rapid environmental change. Essentially, plasticity allows organisms to adjust their phenotypes in developmental time to match current conditions, which (as noted above) contrasts with evolution, where there is 
(a)

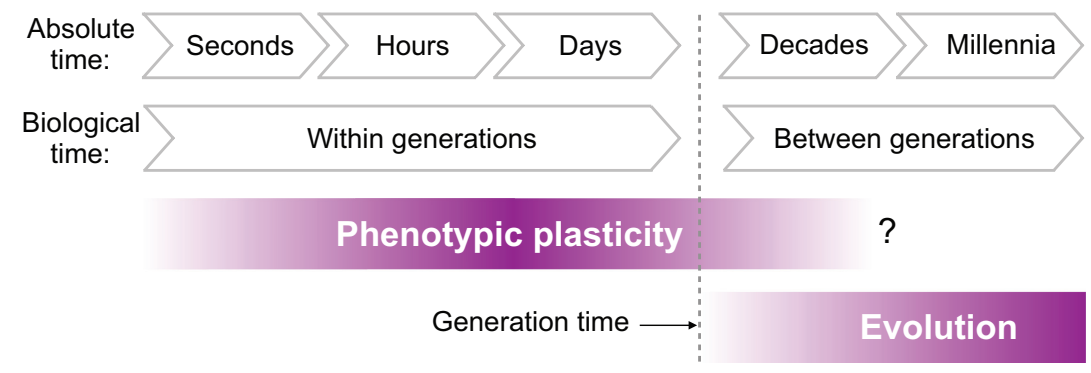

(b)
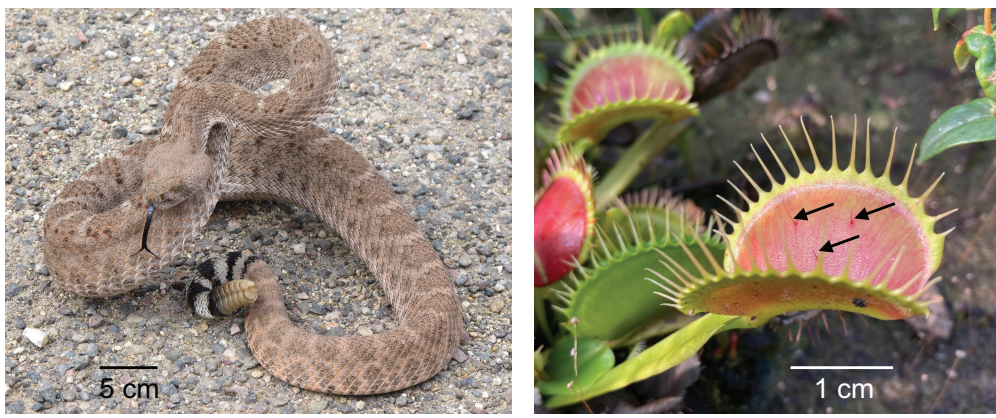

FIGURE 3.2 (a) Plasticity enables organisms to respond to environmental variation within a generation. In contrast, evolution occurs between generations only (some forms of plasticity can also be transmitted between generations). (b) Some plastic responses can occur within seconds of a change in the environment, as when a rattlesnake vibrates its rattle upon being threatened. Even some plants can react to environmental change rapidly. For instance, the Venus flytrap (Dionaea muscipula) can close its leaves and thereby ensnare its prey within 40 milliseconds of its trigger hairs being touched (arrows). More generally, most organisms can alter patterns of gene expression within seconds of a shift in their environment. (Photos: David Pfennig.)

always an intergenerational time lag between when conditions change and when an adaptive response can occur (Figure 3.2).

Moreover, the phenotypic variation wrought by plasticity is often adaptive (see citations above). This widespread adaptiveness of plasticity arises, in part, because plasticity can often be repurposed for another, related environmental context. For instance, recall from above that predation induces increases in body length in Daphnia (Agrawal et al. 1999; see Figure 3.1b). As it turns out, this form of plasticity can be triggered by many different predators, even though the chemical signals that elicit this response likely differ. This predator-resistant phenotype can even be induced by chemicals released by dead Daphnia inside a fish's gut (Stabell et al. 2003). Similarly, many species of plants and animals can respond adaptively to interspecific competition through plasticity-induced niche shifts (see Table 2.1 in Pfennig and Pfennig 2012). These abilities are presumably common because the same response has also evolved as an adaptive solution to intraspecific competition, and the stimuli or cues that trigger the response to one form of competition can also 
trigger the response to the other (Pfennig and Pfennig 2012). Hence, many organisms can generalize environmental stimuli from one context to another, which helps account for plasticity's widespread adaptiveness. Furthermore, as I describe below, because plasticity (like most other traits) is often underlain by genetic variation, it can undergo adaptive evolution such that a particular plastic response becomes better at matching current conditions.

Even in instances where the maintenance or expression of plasticity is costly (DeWitt et al. 1998; and such costs have proved difficult to detect; Auld et al. 2010; Murren et al. 2015; see also Snell-Rood and Ehlman 2021 in this volume), plasticity may still be an optimal strategy. Although an individual with a fixed phenotype might achieve higher fitness than an individual with a plastic phenotype in the environment for which the fixed phenotype is specialized, this fixed phenotype would likely have much lower fitness in a different environment. An individual with a plastic phenotype, by contrast, should have higher fitness overall when averaged across multiple environments (Figure 3.3). Given that environments vary, all organisms are likely to experience such diverse selective regimes, which provides an overall advantage to plasticity.

Of course, not all plasticity is adaptive (Ghalambor et al. 2007; Nettle and Bateson 2015; Palacio-López et al. 2015; Acasuso-Rivero et al. 2019; see also Sultan 2021 in this volume). Indeed, some plasticity appears to be maladaptive, as when organisms confront increasingly stochastic change. For example, climate change is characterized by increased environmental stochasticity (IPCC 2013). Consequently, existing environmental cues for influencing phenology (that is, the timing of any seasonal biological event, such as when plants and animals reproduce, migrate, or go dormant) will likely become less accurate predictors of seasonal progression. As a result, previously adaptive plasticity is more likely to produce mismatches between phenotype and environment. Such maladaptive phenological shifts have been observed in many species (Diamond and Martin 2016; Thackeray et al. 2016).

In sum, plasticity can confer a unique evolutionary advantage by enabling organisms to respond appropriately and immediately to environmental variation. Because environmental variation is commonplace, phenotypic plasticity is also commonplace.

\subsection{QUESTION 2: WHAT ARE THE PROXIMATE MECHANISMS OF PLASTICITY?}

Given that plasticity is ubiquitous, and often adaptive, how does it come about? Biologists have long known that phenotypes can be modified by a diverse array of environmental factors (see Costa 2021 in this volume). Here, I begin our discussion of the mechanisms of plasticity by briefly summarizing how selected environmental factors can induced plastic changes (for a more comprehensive discussion, see Gilbert and Epel 2015; Sultan 2015).

A common trigger of plasticity is temperature. This is hardly surprising given that temperature influences nearly all biochemical and biophysical processes. Although temperature's effects on development are often subtle, these effects can also be profound. For instance, in many turtles, crocodilians, and fish the temperature at which an embryo develops determines its sex. In turtles, researchers recently uncovered 


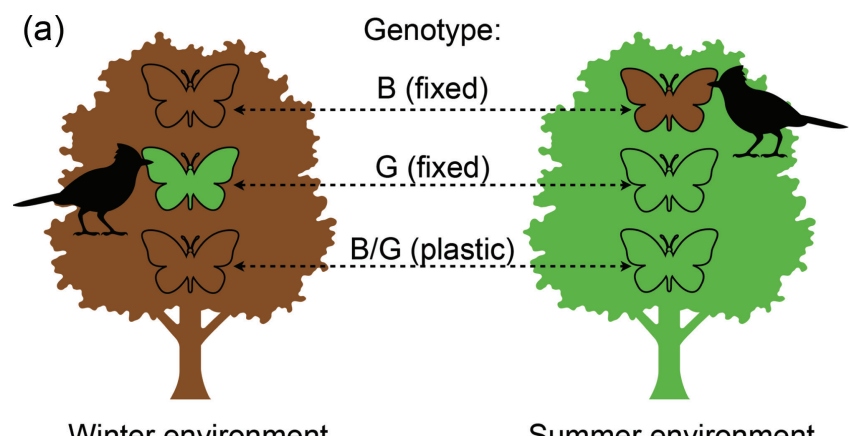

(b)

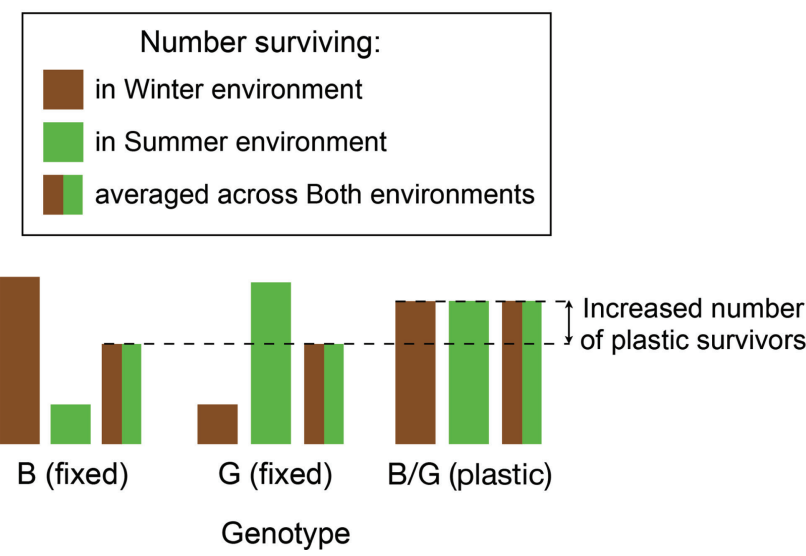

FIGURE 3.3 A fitness advantage of plasticity. Although individuals with fixed phenotypes might achieve higher fitness than individuals with plastic phenotypes in any one environment, plastic individuals should have higher fitness across multiple environments. (a) For example, in the presence of visually oriented predators, camouflaged individuals should suffer less predation. In this hypothetical data set, genotypes that produce fixed green and brown individuals are more likely to be detected by predators in winter (brown) and summer (green) environments, respectively. In contrast, genotypes that produce plastic individuals (that is, individuals that can be either brown or green, depending on their background) are less likely to be detected by predators in either environment. (b) Consequently, plastic genotypes should have higher survival than fixed genotypes when averaged across both environments (for a real-life example, see Noor et al. 2008).

how temperature determines sex: they identified a temperature-sensitive gene that lies in the pathway influencing testes development (Weber et al. 2020).

Another environmental factor that commonly causes plasticity is food. Again, this is not surprising given that food is taken internally and often contains potent chemicals that can induce dramatic phenotypic change. For example, depending on their larval diet, female honeybees develop into either queen or worker castes (castes are a form of discrete plasticity known as a 'polyphenism' [see Figure 3.1c] consisting of behaviorally and [often] morphologically distinct groups within a single colony; Wilson 1971). If fed for most of its larval life a protein-rich diet ('royal 
jelly'), a female will become a queen; otherwise, she will become a sterile worker (Maleszka 2008). This switch happens because royal jelly is rich in both nutritive proteins and a small protein ('royalactin') that increases levels of juvenile hormone (Kamakura 2011). Both increased nutrition and juvenile hormone levels increase the developing honeybee's size, and larger individuals are much more likely to become queens than workers.

Finally, a frequent trigger of plasticity are signals produced by other organisms. For instance, as noted in Section 3.2, many species can detect the presence of predators (sometimes by sensing 'kairomones'; chemicals released by another species) and respond by changing their behavior, physiology, or morphology. Such predatorinduced plasticity is widespread in both plants and animals (Agrawal et al. 1999; see also Figure 3.1b). Other species can sense competitors and respond through adaptive plasticity. For example, in the presence of competitors, colonies of the ant Pheidole pallidula increase the production of distinctive soldier castes to ward off foreign invaders (Passera et al. 1996). Even more impressively, many species of plants and animals can distinguish kin from nonkin and alter their phenotype accordingly (Pfennig and Sherman 1995). For instance, the larvae of western tiger salamanders (Ambystoma mavortium) are less likely to develop into a distinctive cannibal morph (Figure 3.4) when surrounded by kin (Pfennig and Collins 1993), presumably by detecting in the water chemical cues associated with their genetic relatives (Pfennig et al. 1994).

As this brief review makes clear, adaptive plasticity typically involves two main stages: assessment and response (West-Eberhard 2003; Sultan 2015; Levis et al. 2020). Assessment begins when an individual acquires information about its environment. For example, animals have evolved numerous specialized cells and tissues that can receive stimuli from their environment and then translate these stimuli into electrical or chemical signals that the nervous system can decipher (Stevens 2013). Plants have also evolved sophisticated systems to detect changes in their environment and then relay the information to effector systems (Kiss 2006). Once information about the environment is acquired and processed, the individual must then determine how to use that information. More precisely, the individual must 'decide' which of the plausible phenotypes that it could produce will likely yield the highest fitness, given both its environment as well as its own condition (for instance, its energy reserves, health status, age, sex, growth rate, or body size). It is important to emphasize that such assessment need not involve an active decision and may instead be 'passive' (as in the case of temperature-dependent sex determination discussed above). Indeed, even organisms lacking brains can perform sophisticated feats of environmental assessment. Many bacteria, for example, have evolved 'quorum sensing' (Miller and Bassler 2001), where they can gauge the density of bacterial cells in their immediate vicinity and produce (through plasticity) different phenotypes at high population densities. Essentially, natural selection should favor individuals that can gather and use whatever information is available to them to evaluate their environment accurately and effectively.

Understanding how organisms process information during environmental assessment is a largely overlooked frontier in plasticity research. One reason this topic may have been overlooked is longstanding skepticism over whether 
(a)

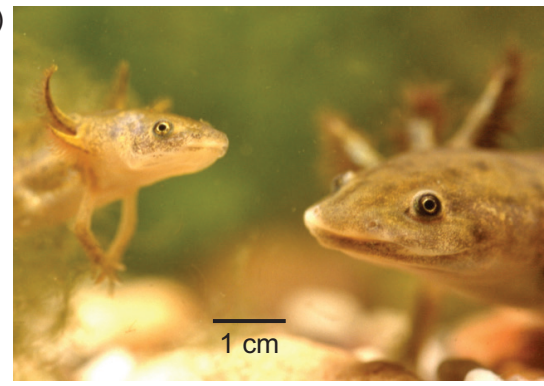

(b)
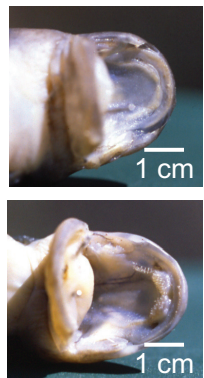

(c)

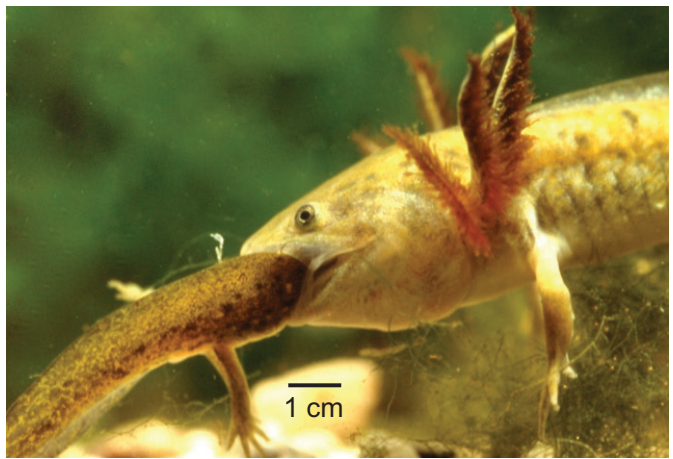

FIGURE 3.4 The presence of genetic relatives suppresses environmentally induced cannibal production in salamanders. (a) Larvae of western tiger salamanders (Ambystoma mavortium) normally develop into a small-headed form that feeds on invertebrates. When crowded, however, some individuals transition from this (b) small-headed, small-toothed form (upper photo) into a large-headed, large-toothed form (lower photo) and become exclusively (c) cannibalistic. Individuals are less likely to produce this cannibal morph when crowded by kin than nonkin. (Photos: David Pfennig.)

nonhuman organisms can evaluate environmental conditions well enough to make adaptive decisions. Yet, we now know that many organisms can carry out complex acts of adaptive environmental assessment, such as optimally choosing what to eat, which sex to become, when to reproduce, with whom to reproduce, and toward whom to allocate aid (Davies et al. 2012). Moreover, like other aspects of the phenotype, assessment mechanisms can undergo adaptive evolution when selection refines pre-existing elements that are sensitive to different environmental circumstances (West-Eberhard 2003).

Once assessment has taken place, the second main stage of adaptive plasticity is a response. Essentially, for adaptive plasticity to occur, assessment must be followed by a developmental change that results in production of a (putatively adaptive) phenotype. As with assessment, this response stage often involves a complex set of mechanisms. For example, considerable research effort has gone into identifying the molecular changes that mediate plastic responses (Lafuente and Beldade 2019). Although these mechanisms are still poorly understood, the best-studied model comes from research into how cells within the same multicellular organism can take 
on different forms and functions, despite being genetically identical. These studies have revealed what role a cell assumes depends on the presence in the cell of special proteins called 'transcription factors' (Gilbert and Epel 2015). Essentially, transcription factors act as switches that turn genes 'on' or 'off,' thereby ensuring that each gene is expressed in the correct cell at the correct time and with the correct level of activity. Importantly, different signals from the external environment can ultimately enlist different transcription factors. Thus, one proposed model for how plasticity comes about is that different environmental stimuli or cues cause different transcription factors to be present within the organism's cells, which causes different genes to be turned on (or off). This process thereby ultimately results in different phenotypes being produced in response to variation in the environment.

Such changes in gene expression may underlie many examples of phenotypic plasticity (Nijhout 2003), but these changes are not the sole way that plasticity might come about. Indeed, there are several means by which environmental signals can modify the patterns of gene expression (Gilbert and Epel 2015). For example, environmental signals might trigger differential gene expression directly, such as when bacteria in an animal's gut induce changes in its intestinal gene expression.

Lastly, when assessing and responding adaptively to their environment, a key challenge all organisms face is distinguishing signal from noise (that is, relevant information from irrelevant information). Generally, natural selection should favor sensory and neural systems that can detect and discriminate a stimulus of importance from background noise. Signal detection theory suggests how adaptive evolution might produce systems that can perform such feats (Wiley 2015). According to this theory, the response threshold (that is, the threshold at which the organism produces one phenotype as opposed to another) should be set where sensory and effector systems are sensitive enough that they correctly detect and respond to a relevant signal but not so sensitive that they respond too frequently to noise. The optimal 'acceptance threshold' (sensu Reeve 1989) is where signal and noise overlap, but where the benefits of responding to the signal (and not to noise) exceed the costs of failing to respond to the signal (or incorrectly responding to noise; Figure 3.5a). This threshold should shift depending on the balance between the aforementioned benefits and costs (Figure 3.5b). Indeed, there is evidence of such threshold shifts in natural populations (Moczek and Nijhout 2003).

In short, studies of the mechanisms of plasticity illustrate how the phenotype emerges from a complex series of developmental, physiological, and even behavioral processes that are influenced by environmental factors as well as by genes (Nijhout 1999). Thus, any particular example of plasticity likely entails many steps, potentially encompassing numerous genes and environmental and physiological factors. This complexity provides copious targets on which selection can act, from the types of signals that an individual's sensory system can detect to the threshold amount of a particular hormone needed to trigger a phenotypic response (Moczek et al. 2011). Clarifying these underlying mechanisms remains an important aim of plasticity research and will be discussed in subsequent chapters of the book (see especially Chenard and Duckworth 2021; Goldstein and Ehrenreich 2021; Ledón-Rettig and Ragsdale 2021 in this volume). 


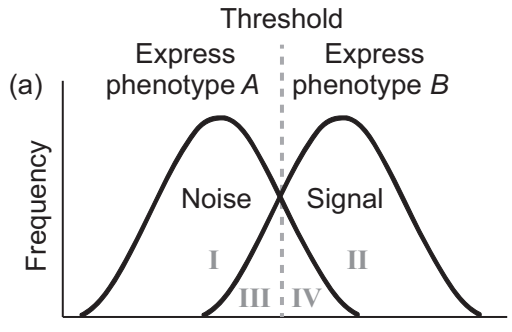

Strength of stimuli or cues

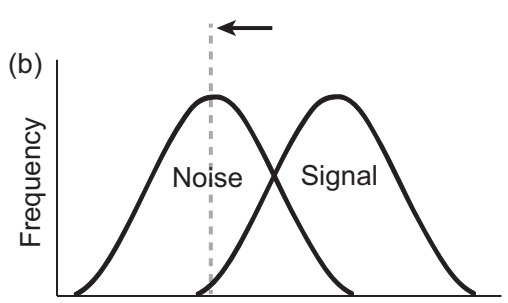

Strength of stimuli or cues

FIGURE 3.5 Signal detection and the expression of adaptive plasticity. (a) When assessing and responding adaptively to their environment, all organisms must discriminate between relevant versus irrelevant information (that is, signal versus noise, respectively). Generally, there should be a threshold value of strength of stimuli or cues (dashed line), above which the organism responds by switching from producing one phenotype (or range of phenotypes; in this case, phenotype $A$ ) to producing an alternative phenotype (or range of phenotypes; in this case, phenotype $B$ ). The optimal location of this threshold will depend on the relative costs and benefits associated with: correctly detecting and responding to the signal (a 'hit': zone II in roman numerals); correctly not responding to noise (a 'good call': zone I); incorrectly failing to respond to a real signal (a 'miss': zone III); or incorrectly responding to noise as a signal (a 'false alarm': zone IV). If these costs and benefits vary, the threshold should shift accordingly. (b) For example, with predator-induced plasticity, failing to detect and respond to an actual predator is often costlier than sometimes falsely responding to a predator that is not actually present. In such cases, the optimal threshold should shift to a lower strength of cues to minimize the chances of a miss (zone III). Theory based on Reeve (1989); figure based on Stevens (2013).

\subsection{QUESTION 3: WHEN SHOULD PLASTICITY EVOLVE, AND WHAT FORM SHOULD IT TAKE?}

As noted above, phenotypic plasticity is probably ancestral to all organisms (Nijhout 2003). Environments have always changed, and every organism appears capable of responding to changes in diverse abiotic and biotic environmental factors. However, not all traits or taxa show similar levels of plasticity (West-Eberhard 2003). In particular, some traits in some lineages are relatively sensitive to environmental influences, whereas others are relatively insensitive (Figure 3.6). What conditions favor increased versus decreased plasticity? Moreover, once plasticity evolves, it can assume different forms (see below). What determines the form that plasticity assumes?

First, greater plasticity (that is, greater environmental influence on the production of a particular trait; Figure 3.6a) should evolve when: (1) organisms confront environmental variation; (2) no fixed trait is best suited for all environmental conditions; (3) individuals can reliably assess their environment; (4) the fitness benefits of expressing plasticity outweigh its costs; and (5) heritable variation for plasticity is present (reviewed in Berrigan and Scheiner 2004; Scheiner 2020; see also SnellRood and Ehlman 2021 in this volume).

Consider, for example, environmental sex determination, a common form of plasticity in certain crustaceans, annelids, fish, and reptiles, where the environment 
(a)

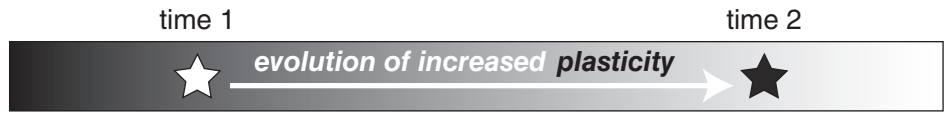

(b)

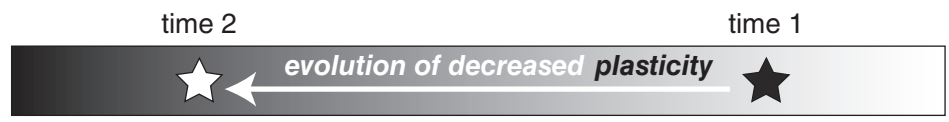

Pure genetic determination

Pure environmental determination

FIGURE 3.6 A schematic depicting the evolution of plasticity, which emphasizes the continuum-and interchangeability — between genetic and environmental influences on phenotype production. Individuals might vary phenotypically either because they carry alternative alleles or because they experienced different environments and their traits' differences arose through phenotypic plasticity. These two proximate mechanisms are best thought of as occupying different positions along a continuum in which strict genetic determination of trait production resides at one end and pure environmental induction resides at the opposite end. However, most (if not all) traits lie between these two extremes (this is why it is meaningless to refer to traits being 'genetically determined' or 'environmentally determined'; nearly all traits are shaped by both genes and the environment). Moreover, a trait's position along this continuum can change over evolutionary time. Specifically, a trait may evolve (a) increased environmental sensitivity (that is, increased plasticity), or (b) decreased environmental sensitivity (that is, decreased plasticity). Such evolutionary shifts in plasticity may, in turn, have important evolutionary consequences. (Modified from Pfennig et al. [2010], with kind permission of the publisher.)

in which an embryo develops determines its sex (Bull 1983; see also the previous section). Charnov and Bull (1977) hypothesized that environmental sex determination should supplant strict genetic determination of sex if the environment in which an individual develops has different fitness consequences for males versus females and if individuals can assess their environment during development. For instance, imagine that a population experiences both 'good' and 'poor' environments, where developing in the good environment is much more beneficial to males than females. As long as individuals can assess which environment they are in, selection should favor environmental sex determination, with (in this hypothetical example) males being produced in the good environment and females in the poor environment.

Support for the Charnov and Bull (1977) model comes from studies of the amphipod crustacean, Gammarus duebeni, which occurs in temperate coastal marshes. This species has evolved environmental sex determination; specifically, an individual's sex is determined by the photoperiod (the length of daylight), with males being produced early in the mating season and females later. Being produced early in the mating season allows more time to grow, and male fitness improves more than female fitness with size (McCabe and Dunn 1997). Thus, because males benefit from larger size more than females, and because individuals can assess their environment (specifically, photoperiod), environmental sex determination - that is, phenotypic plasticity — is adaptive in this system, presumably explaining why such plasticity has evolved. 
Once increased plasticity has evolved, the resulting phenotypes can be distributed continuously or discontinuously, with the former being more common than the latter. Continuous plasticity is referred to as a 'norm of reaction' or simply 'reaction norm' (for an example, see Figure 1.1 in Sultan 2021 in this volume). Reaction norms can allow individuals to finely tune their phenotypic response to the strength of the environmental stimulus. For instance, tadpoles of many species of frogs respond to the presence of predators by developing deeper tails, which enhances their survival. The greater the risk of predation (as measured by the amount of chemicals that predators secrete), the deeper the tail that tadpoles develop (Relyea 2004).

The second main form of plasticity - the occurrence of environmentally induced discrete phenotypes - is referred to as 'polyphenism' (sensu Michener 1961; Mayr 1963, p. 670). Examples of polyphenisms include environmentally influenced sexes (see above); different leaf forms on the same plant ('heterophylly'; Wells and Pigliucci 2000); castes in social insects (Figure 3.1c); seasonal forms produced at different times of the year (Shapiro 1976); alternative reproductive forms in organisms ranging from viruses (Ptashne 2004) to plants (Figure 3.1a) to animals (Pienaar and Greeff 2003; Moczek 2005); certain predator-induced forms (see Figure 3.1b); and alternative resource-use forms found in many organisms (for example, see Figure 3.4). Polyphenisms have long fascinated evolutionary biologists because polyphenisms are thought to represent a key phase in major, lineage-specific innovations (Mayr 1963; Shapiro 1976; West-Eberhard 1989; Nijhout 2003; West-Eberhard 2003). If these alternative phenotypes are subject to independent selection - such that selection acting on one phenotype does not impact the other-then the evolution of a novel phenotype as part of a polyphenism could permit elaboration of that new form without affecting the established phenotype (Snell-Rood et al. 2010; Van Dyken and Wade 2010; Levis and Pfennig 2019; de la Serna Buzon et al. 2020). Thus, clarifying the conditions that favor polyphenism is crucial for understanding the origins of novel phenotypes.

Before discussing the conditions that favor polyphenism, however, it is important to note that most polyphenisms are thought to originate from continuously plastic phenotypes through two different proximate mechanisms (Nijhout 2003). First, polyphenism might emerge from a reaction norm when the environment is discontinuous (or effectively discontinuous, as when the organism experiences it only at discrete times or locations). In such cases, the environment induces only portions of a continuous reaction norm. For example, in bivoltine insects (insects that have two generations per year), each generation develops in a different season and thus experiences different environmental conditions, which can induce different phenotypes (interestingly, when such insects are exposed to intermediate environmental conditions, they often develop intermediate phenotypes not normally seen in nature; Nijhout 1994). Second, polyphenism might arise from a developmental 'switch.' For example, males of the dung beetle Onthophagus taurus have a horn length polyphenism, in which small males are hornless whereas large males have well-developed cephalic horns (Moczek 1998). However, horn length varies allometrically with body size (it increases faster than body size), and the relationship is highly nonlinear. This results in a bimodal distribution of horn sizes, even though body size is normally distributed (Moczek 1998). But what conditions favor the evolution of a polyphenism, especially when the alternative phenotypes co-occur? 
Generally, polyphenism is thought to be favored when disruptive selection acts on continuously varying plasticity (a reaction norm) and molds it into different morphs (where a 'morph' is an individual expressing a distinct morphology or behavior). Disruptive selection occurs when two or more modal phenotypes have higher fitness than the intermediate phenotypes between them because, for example, they are better suited to specific ecological circumstances (Levene 1953; Levins 1968). However, disruptive selection often acts in a frequency-dependent fashion (Bolnick 2004; Rueffler et al. 2006), which means that the fitness of each morph depends on its relative abundance in the population (Sinervo and Calsbeek 2006). Such frequencydependent dynamics typically favor just two morphs (these dynamics can also favor three or more morphs, but this is rare; Sinervo and Lively 1996).

Frequency-dependent disruptive selection is often caused by competition for access to resources or mates (O'Donald 1977; Day and Young 2004). During competitive interactions, the more similar any two individuals are to each other, the more intense the competition between them (Martin and Pfennig 2009). Thus, because each morph competes more against itself than against the alternative morph, frequency-dependent selection favors each morph only when it is rare, thereby preventing any one morph from becoming so common that it supplants the other(s). Consequently, such selection will maintain alternative morphs in a population at frequencies where each morph has, on average, equal fitness. In fact, many polyphenisms are associated with resource or mate acquisition. Figure 3.7 shows how competitive interactions for resources or mates can foster the evolution of a resource polyphenism. Figure 3.8a-d provides an example in which a reaction norm appears to have been refined by selection into a polyphenism.
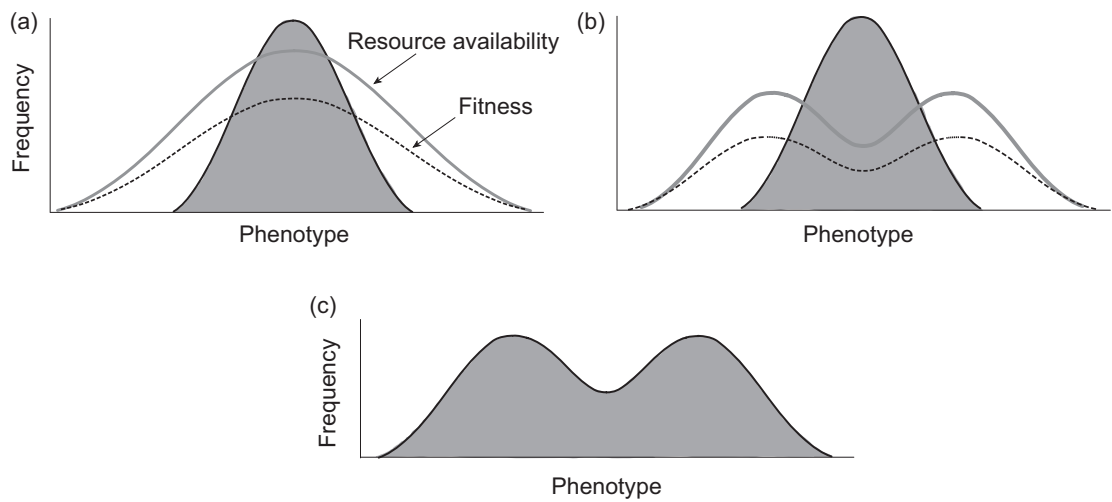

FIGURE 3.7 How disruptive selection can act on continuously varying plasticity in resource use and mold it into a polyphenism. (a) In a population that exploits a range of resource types that are normally distributed (e.g., a range of prey sizes), selection should initially favor those individuals that use the most common resource type (e.g., prey of intermediate size). (b) However, as more individuals exploit this resource type, it becomes depleted over time. Therefore, individuals that use this intermediate resource type will experience more severe competition (and hence, have lower fitness) than those that use extreme, but underexploited, resource types (e.g., very small or very large prey items). (c) Such disruptive selection can eventually promote the evolution of bimodally distributed phenotypes: that is, a polyphenism. 
(a)

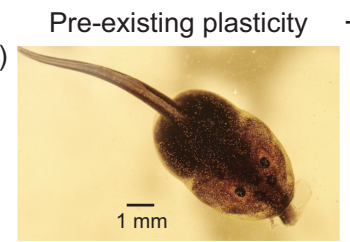

(b)

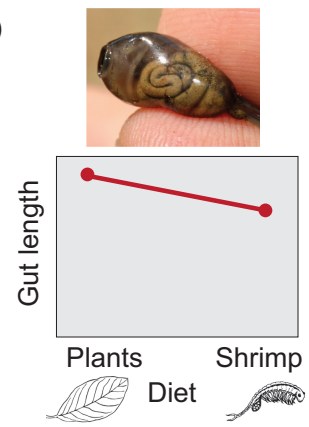

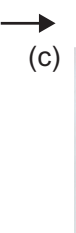

(d)
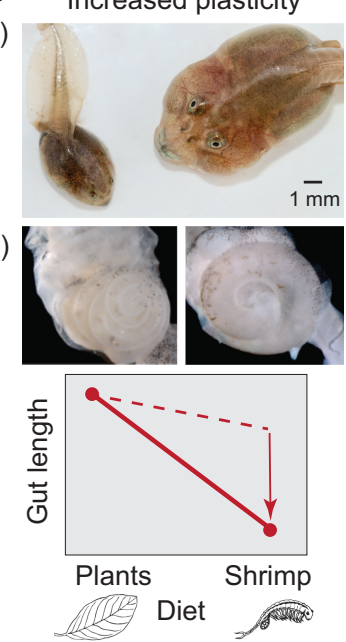
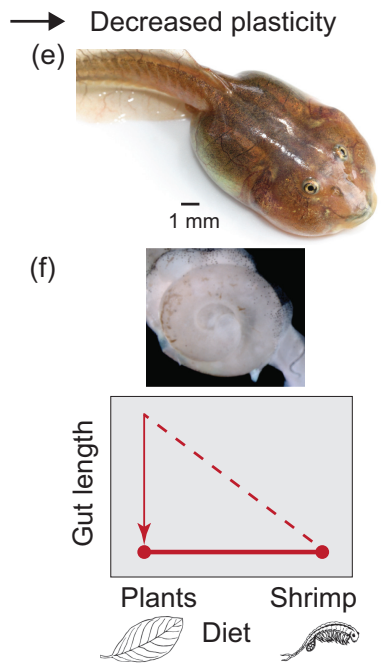

FIGURE 3.8 The evolutionary gain and loss of plasticity, as illustrated in tadpoles of New World spadefoot toads (genera Scaphiopus and Spea). (a) Scaphiopus tadpoles-like the tadpoles of many frogs and toads, appear to harbor pre-existing, diet-induced plasticity. Although they normally develop into a generalized 'omnivore' morph, if they eat large animal prey (such as freshwater shrimp or other tadpoles), (b) they develop a slightly shorter gut. (c) In Spea, this diet-induced plasticity has been enhanced as part of a polyphenism, in which individuals that eat meat deviate from the default omnivore morph (left) and develop into a distinctive 'carnivore' morph (right), which (d) produces a dramatically shorter gut (the dashed line indicates the presumed ancestral condition; the arrow indicates the direction of the evolutionary change in plasticity). (e) Finally, this diet-induced plasticity has been lost in certain derived populations of Spea, which always produce the carnivore morph (f) with its short gut, regardless of their diet. Based on Ledón-Rettig et al. (2008; 2010), Levis et al. (2018), and Levis and Pfennig (2019). (Photos: David Pfennig.)

As the above discussion makes clear, selection can act on pre-existing plasticity to extend and refine it. Indeed, there is abundant evidence from diverse group of plants and animals that plasticity has undergone evolutionary change, even among closely related lineages (Schwander and Leimar 2011; Murren et al. 2014). However, not only can a particular lineage evolve an increase in plasticity, it can also evolve a decrease in plasticity, where a trait becomes less responsive to a specific change in the environment (Figure 3.6b). Such decreased plasticity might evolve for at least two reasons. First, when plasticity is costly (Snell-Rood et al. 2010; Murren et al. 2015; see also Snell-Rood and Ehlman 2021 in this volume), selection can actively eliminate it, leading to the fixation of the favored phenotype through an evolutionary process known as 'genetic assimilation' (Waddington 1942; sensu Waddington 1953; for examples from natural populations, see Figure 3.8e, $\mathrm{f}$ as well as Scheiner and Levis 2021 in this volume). However, plasticity might also be lost through mutational degradation or genetic drift (Masel et al. 2007), as may occur when non-favored phenotypes are seldom expressed and thereby experience relaxed selection (Kawecki 1994; Whitlock 1996; Van Dyken and Wade 2010). 
In sum, plasticity can evolve and assume different forms. Plasticity's evolution may, in turn, have important downstream consequences for evolution more generally, which is the topic I turn to next.

\section{BOX 3.2 PLASTICITY AND EVOLUTION: A BRIEF HISTORY}

Prior to the 20th century, most scholars held that: (1) an individual's environment influenced its traits, and (2) environmentally altered features could be passed to offspring (Zirkle 1946; see also Costa 2021 in this volume). These beliefs stemmed from two common observations: (a) that both plants and animals are modified by environmental change (in modern terms, they display plasticity), and (b) that offspring resemble their parents. Although point 2 above-the socalled 'inheritance of acquired characters'-is often associated with the French biologist Jean-Baptiste Lamarck (1744-1829), Lamarck never actually regarded it as his seminal contribution (Burkhardt 2013). Instead, Lamarck merely treated a concept that had been around for at least two millennia as self-evident (Zirkle 1946). Even Charles Darwin (1809-1882) accepted these ideas when he developed his grand theory of 'pangenesis' to explain how the inheritance of acquired characteristics might operate (Galton 2018; Costa 2021).

The person credited with 'disproving' the inheritance of environmentally induced traits was the German biologist August Weismann (1843-1914). In a lecture delivered in 1883 (entitled "On Inheritance"; translated in Mayr 1985), Weismann made a compelling argument against the inheritance of acquired characters. In doing so, he discussed case after case in which variation could not be explained by use and disuse. For example, Weismann asked: How can the numerous special adaptations of the workers and soldiers of ants be inherited by use, when these individuals do not reproduce? From these case studies, Weismann concluded that "the improvement of an organ in the course of generations is not the result of a summation of the result of practice of individual lives, but of the summation of favorable genetic factors" (1883, p. 26). Following this sweeping rejection of the inheritance of acquired characters, the idea never regained full credibility (it is worth noting, however, that Weismann's views on this subject were actually more nuanced than is often depicted; Winther 2001).

Two decades after Weismann's lecture, the field of genetics took off when three scientists independently 're-discovered' the work of the Moravian monk Gregor Mendel (1822-1884). In a paper published in an obscure journal in 1866, Mendel had deduced how parents pass to their offspring discrete, invisible 'factors' - now called genes - that predictably influence the traits of their offspring. In the 1930s, Mendel's insights were merged with the mathematical models of R. A. Fisher, J. B. S. Haldane, and Sewall Wright to form the basis for the 'Modern Synthesis' of evolutionary biology (Huxley 1942 [2009]). One consequence of this synthesis was that the phenotype was thereafter 
viewed as a direct readout of the genotype. With few exceptions (Haldane 1946), any effects of the environment on the phenotype were treated as 'noise' not worthy of attention (Falconer 1952). To the degree that any such variation was acknowledged, it was given a genetic explanation by such new terms as 'penetrance' and 'expressivity' (Sakar 1999). Skepticism about plasticity's role in evolution likely stemmed from the tendency to invoke the inheritance of acquired characters whenever discussing plasticity (see example in main text). Plasticity was also scorned in the mid-20th century because of the highly influential—but dangerously flawed-work of the Soviet agronomist Trofim Lysenko (Graham 2016).

At the same time, five scientists were critical in suggesting that plasticity can play an important role in evolution (see also Futuyma 2021 in this volume). The first is the American psychologist James Baldwin (1861-1934; Figure 3.9a), who, in 1896, developed an idea that came to be known as the 'Baldwin effect' (sensu Simpson 1953). According to Baldwin (1896): (1) when the environment changes dramatically, selection favors those individuals that are behaviorally or morphological flexible; (2) the descendants of these individuals breed with each other in the new environment; and (3) eventually, any behavior or morphological change brought about by the new environment becomes congenital (or, in modern terms, genetically fixed). Although Baldwin's ideas remain controversial, he was among the first to link plasticity among individuals to evolution by suggesting that environmentally induced traits can evolve (Gottlieb 1992; Robinson and Dukas 1999; Webber and Depew 2003; Crispo 2007; Badyaev 2009; Scheiner 2014).

Baldwin's ideas were extended by the Russian biologist Ivan Schmalhausen (1884-1963; Figure 3.9b). In his book, Factors of Evolution: The Theory of Stabilizing Selection, Schmalhausen (1949 [1986]) argued that a new morphological adaptation starts out as an environmentally induced form following a change in the environment. Later, the adaptation comes under internal control ('stabilizing selection') and is genetically fixed. As empirical support, Schmalhausen provided numerous examples of discrete, environmentally induced alternative phenotypes (polyphenisms) that appear to have become genetically fixed in other lineages.

Shortly thereafter, the British geneticist Conrad Waddington (1905-1975; Figure 3.9c) demonstrated experimentally that an environmentally induced trait could indeed become genetically fixed as a result of persistent selection. In his most famous experiment, Waddington (1953) subjected a group of fruit flies to a heat shock during embryonic (pupal) development (a separate control group was not heat shocked but treated the same otherwise). As adults, some of these flies exposed to heat shock developed wings with few or no crossveins. Waddington selected these crossveinless flies for breeding and subjected their offspring to the heat shock, once again selecting crossveinless flies for breeding (and, once again, maintaining a control group). After repeating 
(a)

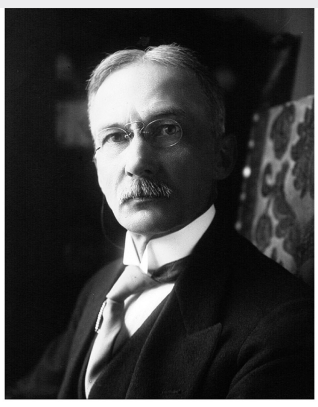

(b)

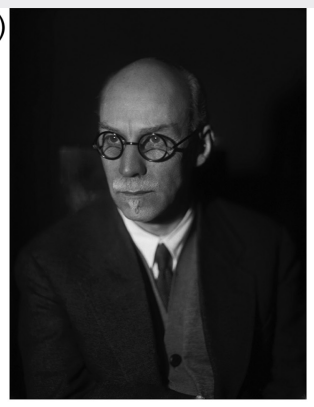

(c)

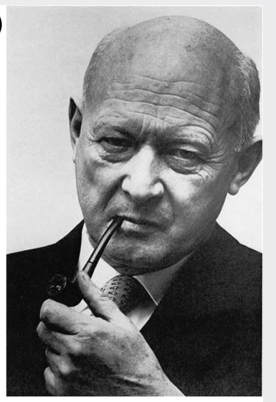

(d)

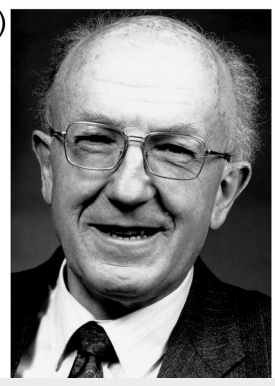

(e)

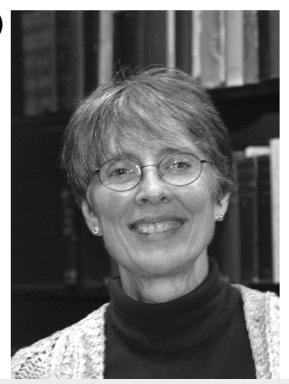

FIGURE 3.9 Key figures in the study of plasticity and evolution. (a) James Baldwin; (b) Ivan Schmalhausen; (c) Conrad Waddington; (d) Anthony Bradshaw; and (e) Mary Jane West-Eberhard. (Photo credits: [a] public domain; [b] Alamy, reproduced with permission; [c] from Robertson [1977], reproduced with the kind permission of the Royal Society; [d] from Fitter [2010], reproduced with the kind permission of the Royal Society; [e] courtesy of Mary Jane West-Eberhard.)

this procedure for 14 generations, Waddington noted that a small proportion of flies in the control group expressed the crossveinless phenotype. This was surprising because, although the ancestors of these control flies had been exposed to heat shock in earlier generations, they had not. Thus, a trait that was originally triggered by the environment had lost this environmental sensitivity and become fixed, a process Waddington (1953) dubbed 'genetic assimilation.'

Waddington's experiments were pathbreaking for he had shown that: plasticity can be underlain by heritable variation (he later argued that different genotypes of flies likely differed in how they responded to the heat shock); selection could act on this variation to promote evolution; and such selection could even cause plasticity to be lost (see Scheiner and Levis 2021 in this volume). Yet, Waddington's experiments were largely ignored. Indeed, prominent evolutionists such as Mayr (1963) and Dobzhansky (1970) misinterpreted genetic assimilation as an attempt to resurrect the (by now largely discredited) idea of the inheritance of acquired characters (see above; this misunderstanding 
is perhaps only natural given the title of Waddington's seminal 1953 paper: Genetic Assimilation of an Acquired Character).

The modern era of plasticity research did not begin, however, until 1965. The key event was the publication of a paper by the British ecologist Anthony Bradshaw (1926-2008; Figure 3.9d). In his paper, Bradshaw (1965) made two important points. First, rather than being simply noise, environmental effects on the phenotype were as important as genetic effects. Second, these effects were themselves under genetic control and could therefore undergo adaptive evolution in response to environmental variation. Indeed, Bradshaw emphasized how different genotypes within the same population typically vary in whether and how they respond to a particular change in environment (as Waddington had proposed and as some early architects of the Modern Synthesis had actually initially suggested; see, for example, Haldane 1946). Such genetic variation in plasticity is now dubbed 'genotype-environment interaction' or simply 'G×E' (see Sultan 2021 in this volume). Following the publication of Bradshaw's paper, researchers began to view phenotypic plasticity as a trait that could undergo adaptive evolution. Bradshaw's paper was also instrumental in bringing plasticity to the attention of a new generation of researchers, especially ecologists and field biologists, who were then motivated to study plasticity in natural populations.

Finally, in 2003, the American behavioral ecologist Mary Jane WestEberhard (1941-; Figure 3.9e) published a highly influential book, Developmental Plasticity and Evolution, in which she argued that most phenotypic evolution begins with environmentally mediated developmental change; that is, plasticity (see also West-Eberhard 2021 in this volume). Specifically, West-Eberhard (2003) proposed that adaptive evolution involves four steps. First, a distinctive developmental variant is produced when a mutation or an environmental stimulus triggers a change in phenotype. Second, a process of 'phenotypic accommodation' occurs when plasticity improves the functioning of the novel phenotype through immediate, additional changes in development. Third, the initiating factor recurs, producing a subpopulation of individuals that express the trait. Finally, a process of 'genetic accommodation' - a sort of adaptive refinement-follows, in which gene frequencies change due to selection on the regulation and/or form of the novel trait (Waddington's concept of genetic assimilation is one extreme form of genetic accommodation, in which the regulation of plasticity evolves to the point at which plasticity is lost and the trait becomes fixed; another extreme is polyphenism, where environmental responsiveness is accentuated and adaptively refined; see Figure 3.1 and Section 3.4). Notably, West-Eberhard marshaled an impressive array of evidence to support these arguments. Consequently, her book stimulated considerable discussion and research (as can be gleaned from many of the chapters in this volume). 


\subsection{QUESTION 4: CAN PLASTICITY INFLUENCE EVOLUTION?}

Although many early naturalists were well aware that the environment could alter an organism's traits - and some even viewed this plasticity as a potent driver of evolution - these ideas were largely swept aside by the emergence of genetics in the 20th century (see Box 3.2; see also Costa 2021 in this volume). Indeed, with the development of the 'Modern Synthesis' of evolutionary biology (the reconciliation of Darwin's theory with Mendelian genetics; see Box 3.2), plasticity came to be regarded as irrelevant to the evolutionary process. According to this view, plasticity cannot affect evolution because evolution requires heritable change, and (the argument went) plasticity cannot be inherited (see, for example, Dobzhansky 1970, p. 32). However, there are two problems with this argument. First, as I describe below, plasticity can impact evolution even when the specific plastic response itself is not inherited. Second, as I also describe below, some plastic responses can, in fact, be inherited.

However, saying that plasticity can influence evolution is not tantamount to saying that it promotes evolution. Indeed, because plasticity enables a single genotype to produce multiple phenotypes in response to different environmental conditions, any further genetic change may not be required to adapt to new conditions. In such situations, plasticity might dampen diversifying selection and, hence, evolution (Wright 1931). Or, as Mayr (1963, p. 147) put it:

The ability of the phenotype to respond to the demands of the environment without mutation greatly reduces selection pressure.

Consistent with this idea, there are cases in which plasticity appears to have slowed evolution (Bogert 1949; Huey et al. 2003; Oostra et al. 2018).

However, not everyone agrees that plasticity always impedes evolution. Indeed, some have long hypothesized that plasticity promotes (and in some cases even supplants) genetic evolution. Although various hypotheses have been proposed for how plasticity might facilitate evolution (including 'the Baldwin effect,' 'stabilizing selection,' 'genetic assimilation,' and 'genetic accommodation;' see Box 3.2), all such hypotheses assume that adaptive evolution unfolds when environmentally induced phenotypes appear first, followed by adaptive refinement of this plasticity.

Here, I examine three, non-mutually exclusive routes by which plasticity can facilitate evolution (summarized in Table 3.1; see also Wund 2012). First, plasticity can facilitate evolution indirectly by promoting population persistence in novel environments, thereby allowing populations to remain viable until adaptive evolution can occur (the 'buying time' hypothesis). Second, plasticity can facilitate evolution directly by exposing formerly unexpressed genetic variation to selection, thereby fueling adaptive evolution (the 'plasticity-led evolution' hypothesis). Lastly, plasticity can facilitate evolution directly by forming the basis for an alternative inheritance system on which adaptive evolution can unfold (the 'non-genetic evolution' hypothesis). Below, I discuss each route in turn.

First, plasticity can facilitate evolution by promoting population persistence in novel environments. This hypothesis traces to the late 19th century-most notably, 


\section{TABLE 3.1}

\section{Alternative Ways That Plasticity Has Been Hypothesized to Impact Evolution}

1. Plasticity does not affect evolution because it cannot be inherited.

2. Plasticity impedes evolution by shielding genotypes from selection.

3. Plasticity facilitates evolution by:

a. promoting population persistence in novel environments (the 'buying time' hypothesis).

b. exposing 'cryptic' genetic variation to selection, thereby fueling adaptive evolution (the 'plasticity-led evolution' hypothesis).

c. forming an alternative inheritance system on which adaptive evolution can unfold (the 'non-genetic inheritance' hypothesis).

to the psychologist James Baldwin (1896)—who proposed that, in a rapidly changing environment, selection will favor individuals that are plastic, because these individuals will be more likely to adapt to such changing circumstances (see Box 3.2). This idea, which came to be known as the 'Baldwin effect' (Simpson 1953; see recent reviews in Crispo 2007; Scheiner 2014), was stated succinctly by the paleontologist E. D. Cope (1896, p. 174), who maintained that the most successful lineages in evolution were invariably those that:

... presented a combination of effective structures with plasticity, which has enabled them to adapt themselves to changed conditions.

Plasticity promotes population persistence in rapidly changing environments because of its unique ability to generate phenotypes that match current environmental conditions (see Section 3.2). If, instead, the production of these phenotypes requires favorable mutations, the waiting time can be prohibitively long (Charlesworth 2020), which increases the chances that a population under stress will go extinct. By enhancing population persistence, plasticity fosters evolution indirectly by 'buying time' until genetically based adaptations to accommodate any new conditions can evolve (Diamond and Martin 2016; Scheiner et al. 2017; Fox et al. 2019; see also Diamond and Martin 2021 in this volume). Essentially, plasticity can promote 'evolutionary rescue,' which occurs when evolution by natural selection prevents a population from going extinct (Gomulkiewicz and Holt 1995; see also Snell-Rood et al. 2018 for a discussion of the related concept of 'plastic' rescue). As evidence that plasticity might reduce extinction risk, birds that exhibit higher levels of behavioral plasticity (as measured by a higher propensity to innovate) are at a lower risk of extinction - that is, they are more likely to have increasing or stable populations - than birds that exhibit lower levels of such plasticity (Ducatez et al. 2020). Generally, most researchers probably view this buying time hypothesis as the primary way that plasticity facilitates evolution (Pennisi 2018; Fox et al. 2019).

The second main route by which plasticity can facilitate evolution is through 'plasticity-led evolution' (sensu Levis and Pfennig 2019) (sometimes referred 
to as 'plasticity-first evolution'; sensu Schwander and Leimar 2011; Levis and Pfennig 2016). In contrast with the traditional process of mutation-led evolution, where a new phenotype first appears following a change in the genome (Carroll 2008), with plasticity-led evolution a new phenotype first appears following a change in the environment. To understand how this process works, consider that most natural populations contain a large reservoir of genetic variation that is not expressed phenotypically under normal conditions (Lewontin 1974). This 'cryptic' genetic variation can be expressed phenotypically, however, when organisms experience novel (or stressful) conditions, such as a change in the environment (Gibson and Dworkin 2004; Ledón-Rettig et al. 2014). The phenotypic expression of this variation is crucial because selection acts on phenotypes; not genotypes. However, selection can only act on those phenotypes that are actually expressed.

Once these phenotypes are expressed, selection can act on them and essentially favor the underlying genotypes that are associated with phenotypes that are well adapted for the current environment. As long as the altered environment persists, selection could continue to promote quantitative genetic changes and mold the environmentally induced phenotype into a new adaptive form. Such a process of 'genetic accommodation' can cause a change in both the regulation of plasticity and the form of the phenotype, leading to a better match between phenotype and environment (West-Eberhard 2003). Of course, as with any adaptive evolution, the speed and magnitude of this response depend on the strength of selection and how much genetic (more generally, heritable) variation for plasticity is present. The key point is that the heritable variation that fuels this response is revealed to selection by plasticity.

Ultimately, plasticity-led evolution may result in a new phenotype that was not present in the ancestral population, at least not in a well-adapted form (for an example, see Figure 3.8; see also Suzuki and Nijhout 2006). This process might play an underappreciated role in evolutionary innovation and diversification/speciation (see Levis and Pfennig 2021 in this volume). Plasticity-led evolution has also been implicated in triggering adaptive radiation (West-Eberhard 2003; Wund et al. 2008; Pfennig and McGee 2010; Schneider and Meyer 2017), promoting the origins of multicellularity (see Davison and Michod 2021 in this volume), and mediating various other macroevolutionary events (see Lister 2021 in this volume).

Lastly, a third (and by far most controversial) route by which plasticity can facilitate evolution is when environmentally induced responses form an alternative inheritance system on which adaptive evolution can unfold rapidly. In recent years, it has become increasingly clear that vital information can be acquired from parents (that is, inherited) not only through genes but also through various non-genetic factors (factors not encoded by the genomic DNA sequence; reviewed in Bonduriansky and Day 2018). Like genes, such factors can influence the phenotypes of offspring and possibly even mediate evolutionary change (Bonduriansky and Day 2009; Danchin et al. 2011). For example, in many Eukaryotes (the group that includes plants, animals, fungi, and protozoans), the addition of a methyl group $\left(\mathrm{CH}_{3}\right)$ to a DNA strand 
can influence when, where, and how much the genes on that strand are expressed (Jones 2012; Aliaga et al. 2019). Although some such methyl 'tags' are encoded by the genomic DNA sequence itself, others can be induced by environmental triggers, such as diet or stress (Dominguez-Salas et al. 2014; Miryeganeh and Saze 2020). Once induced, these 'epigenetic' factors can even be transmitted across generations independently of DNA sequence changes. (As an aside, the meaning of the term 'epigenetic' has changed over the years. It was coined by Conrad Waddington in the 1940s to refer to the interaction between genes and environment that results in the production of a phenotype. Now 'epigenetic' often refers to changes in a phenotype caused by modification of gene expression rather than alteration of the genetic code itself.) For example, in the case of DNA methylation, special enzymes (methyltransferases) can copy a methyl tag from the parent strand onto the daughter strand during DNA replication (Wang et al. 2017; Bonduriansky and Day 2018). In this way, an environmentally induced change in gene expression (and, hence, potentially in phenotype) can be inherited.

As additional examples of non-genetic factors that can influence the phenotypes of offspring and possibly even mediate evolutionary change, parents of many species often differentially endow their seeds, eggs, or offspring with acquired information or materials (cytoplasm, hormones), which can then influence their offspring's phenotype (Mousseau and Fox 1998). Although experiences acquired during an individual's lifetime are typically transmitted to offspring only through 'somatic' cells (any cell forming the body of a multicellular organism other than the gametes ['germline']), in some cases, such information can be transported to the germline, where it may then become more permanently encoded (O'Brien et al. 2020). Through this process, an environmentally induced phenotype can be inherited.

Although it is unclear for how many generations, or how reliably, such 'transgenerational plasticity' can be inherited in natural populations, these effects can arise rapidly (because they can be induced within a generation by a change in the environment) and are known to mediate adaptive change in the wild (Galloway and Etterson 2007). However, even if transgenerational plasticity can be passed down for only a few generations, it might still be important in increasing the chances that a lineage will persist until more permanent genetic changes evolve (in which case, this route merges with the buying time hypothesis above). Bonduriansky (2021) discusses transgenerational plasticity in greater detail later in this volume.

In sum, contrary to widespread claims to the contrary, there are circumstances under which plasticity might actually promote evolution. Specifically, plasticity might facilitate evolution by buying time until adaptive evolution can occur, by uncovering genetic variation that fuels evolution, or by forming an alternative inheritance system on which evolution can unfold. As we will see in subsequent chapters, each of these three routes has both theoretical and empirical support. At the same time, more research is needed. For now, having established a possible role for plasticity in evolution, I turn to our final question: does plasticity fit within the existing evolutionary theory? 


\subsection{QUESTION 5: DOES PLASTICITY FIT WITHIN EXISTING EVOLUTIONARY THEORY?}

As noted in Box 3.2, evolutionists have long struggled with whether and how to incorporate plasticity into their framework. Recently, some have suggested that fully integrating plasticity into evolutionary theory will require revamping the Modern Synthesis of evolutionary biology (Pigliucci 2007; Laland et al. 2014, 2015; Pigliucci and Finkelman 2014).

Later chapters will explore this controversy in greater detail (see especially Futuyma 2021; Levis and Pfennig 2021; Schlichting 2021 in this volume), so I will be brief here. Specifically, I emphasize for now that plasticity fits comfortably within existing evolutionary theory. For example, all three routes by which plasticity can facilitate evolution outlined in Table 3.1 are consistent with modern evolutionary theory: each involves selection acting on heritable variation, which is the standard model of how adaptive evolution works that has held for over 150 years.

At the same time, knowledge of plasticity can enhance our understanding of evolution by emphasizing how the environment can both select on phenotypic variation and help generate that variation in the first place (Matsuda 1987, p. 53). Consequently, incorporating plasticity into evolutionary thinking can illuminate a broader array of evolutionary phenomena, such as how evolution can unfold rapidly, why similar phenotypes are often produced in similar environments, and how novel complex traits evolve.

In sum, while the existence of plasticity does not challenge Darwin's fundamental insight that natural selection, coupled with inheritance, propels adaptive evolution, it does provide a richer view of the evolutionary process.

\subsection{CONCLUSIONS}

Phenotypic plasticity has long perplexed biologists, and an increasing number of researchers have recently sought to clarify its causes and consequences. As we have seen, plasticity is often beneficial: it can uniquely enable individual organisms to respond appropriately to environmental change during their lifetime. In this way, organisms can potentially track rapidly changing environments, such as those that many natural populations experience. Recent studies have also begun to uncover the mechanisms of plasticity. These studies have revealed that plasticity typically involves numerous genetic, physiological, behavioral, and environmental factors, which provide plentiful targets on which selection can act when promoting either increased or decreased plasticity.

As we have also seen, although plasticity can sometimes impede evolution, it is thought to facilitate evolution through at least three main routes: (1) by promoting population persistence in novel environments, thereby allowing populations to remain viable until adaptive evolution can occur (the 'buying time' hypothesis); (2) by exposing cryptic genetic variation to selection, thereby fueling adaptive evolution (the 'plasticity-led evolution' hypothesis); or (3) by constituting an alternative 
inheritance system on which adaptive evolution can unfold (the "non-genetic evolution' hypothesis). Incorporating these routes more fully into evolutionary thinking will provide a richer perspective on how adaptive evolution works by emphasizing that the environment can both select on phenotypic variation and help generate that variation in the first place.

More generally, a broader understanding of plasticity will likely impact all fields of biology, as it will necessarily require that researchers confront two facts about biological systems: first, that most traits emerge from an interaction between an individual's genes and its environment, and second, that individual variation and flexibility are the rule rather than the exception. Although more research on plasticity is needed (Box 3.3), future studies promise to provide important new insights into how organisms develop, function, interact with each other, and evolve.

\section{BOX 3.3 SUGGESTIONS FOR FUTURE RESEARCH}

- Clarify the underlying mechanisms of plasticity. More studies are needed to determine how organisms assess and respond to environmental variation.

- Perform more empirical tests of the theoretical conditions that favor plasticity's evolution. Ideally, such studies should be conducted in both natural populations and experimental evolution studies (Garland and Kelly 2006).

- Determine if, in variable environments, lineages that express higher levels of plasticity are more likely to persist and evolve more rapidly than those that express lower levels. Again, such studies should be conducted in both natural populations and experimental evolution studies.

- Develop the theory, and conduct additional empirical tests of that theory, on whether and how plasticity impacts evolution. More theoretical and empirical work is needed to identify the conditions under which plasticity fails to impact evolution, impedes it, or facilitates it.

- Evaluate whether and how plasticity affects ecology. Because plasticity can enable organisms to respond to other species (competitors, predators, mutualists) rapidly and adaptively, it might thereby influence the composition of ecological communities as well as the selective agents that impinge on its members. More studies are needed, however, to establish whether and how plasticity affects ecology (for example, see Agrawal 2001; Fordyce 2006; Pfennig and Pfennig 2012; Hendry 2016) 


\section{ACKNOWLEDGMENTS}

For commenting on earlier drafts of this chapter, I thank Karin Pfennig, Nick Levis, Emily Harmon, Andrew Isdaner, Pat Kelly, Sonia Sultan, and Mary Jane West-Eberhard.

\section{REFERENCES}

Acasuso-Rivero, C., C. J. Murren, C. D. Schlichting, and U. K. Steiner. 2019. Adaptive phenotypic plasticity for life-history and less fitness-related traits. Proceedings of the Royal Society B: Biological Sciences 286:20190653.

Agrawal, A. A. 2001. Phenotypic plasticity in the interactions and evolution of species. Science 294:321-326.

Agrawal, A. A., C. Laforsch, and R. Tollrian. 1999. Transgenerational induction of defences in animals and plants. Nature 401:60-63.

Aliaga, B., I. Bulla, G. Mouahid, D. Duval, and C. Grunau. 2019. Universality of the DNA methylation codes in Eucaryotes. Scientific Reports 9:173.

Auld, J. R., A. A. Agrawal, and R. A. Relyea. 2010. Re-evaluating the costs and limits of adaptive phenotypic plasticity. Proceedings of the Royal Society B: Biological Sciences 277:503-511.

Auld, J. R. and R. Relyea. 2011. Adaptive plasticity in predator-induced defenses in a common freshwater snail: Altered selection and mode of predation due to prey phenotype. Evolution and Ecology 25:189-202.

Badyaev, A. V. 2009. Evolutionary significance of phenotypic accommodation in novel environments: An empirical test of the Baldwin effect. Proceedings of the Royal Society, Series B 364:1125-1141.

Baldwin, J. M. 1896. A new factor in evolution. The American Naturalist 30:441-451.

Barnett, L. L., A. Troth, and J. H. Willis. 2018. Plastic breeding system response to day length in the California wildflower Mimulus douglasii. American Journal of Botany 105:779-787.

Bateson, P., D. Barker, T. Clutton-Brock, D. Deb, B. D‘Udine, R. A. Foley, P. Gluckman, K. Godfrey, T. Kirkwood, M. M. Lahr, J. McNamara, N. B. Metcalfe, P. Monaghan, H. G. Spencer, and S. E. Sultan. 2004. Developmental plasticity and human health. Nature 430:419-421.

Berrigan, D. and S. M. Scheiner. 2004. Modeling the evolution of phenotypic plasticity, pp. 82-97. In T. J. DeWitt, and S. M. Scheiner, eds., Phenotypic Plasticity: Functional and Conceptual Approaches. Oxford University Press, New York.

Bogert, C. M. 1949. Thermoregulation in reptiles, a factor in evolution. Evolution 3:195-211.

Bolnick, D. I. 2004. Can intraspecific competition drive disruptive selection? An experimental test in natural populations of sticklebacks. Evolution 58:608-618.

Bonduriansky, R. 2021. Plasticity across generations. In D. W. Pfennig, ed., Phenotypic Plasticity and Evolution: Causes, Consequences, Controversies. CRC Press, Boca Raton, FL.

Bonduriansky, R. and T. Day. 2009. Nongenetic inheritance and its evolutionary implications. Annual Review of Ecology, Evolution and Systematics 40:103-125.

Bonduriansky, R. and T. Day. 2018. Extended Heredity: A New Understanding of Inheritance and Evolution. Princeton University Press, Princeton, NJ.

Bradshaw, A. D. 1965. Evolutionary significance of phenotypic plasticity in plants. Advances in Genetics 13:115-155.

Bull, J. J. 1983. Evolution of Sex Determining Mechanisms. Benjamin/Cummings, Menlo Park, CA. 
Burkhardt Jr., R. W. 2013. Lamarck, evolution, and the inheritance of acquired characters. Genetics 194:793-805.

Carroll, S. B. 2008. Evo-devo and an expanding evolutionary synthesis: A genetic theory of morphological evolution. Cell 134:25-36.

Caruso, C. M., H. Maherali, and M. Sherrard. 2006. Plasticity of physiology in Lobelia: testing for adaptation and constraint. Evolution 60:980-990.

Charlesworth, B. 2020. How long does it take to fix a favorable mutation, and why should we care? The American Naturalist 195: 753-771.

Charnov, E. L. and J. J. Bull. 1977. When is sex environmentally determined? Nature 266:828-830.

Chenard, K. and R. A. Duckworth. 2021. The special case of behavioral plasticity? In D. W. Pfennig, ed., Phenotypic Plasticity and Evolution: Causes, Consequences, Controversies. CRC Press, Boca Raton, FL.

Cope, E. D. 1896. The Primary Factors of Organic Evolution. The Open Court Publishing Co., Chicago, IL.

Costa, J. T. 2021. There is hardly any question in biology of more importance-Charles Darwin and the nature of variation. In D. W. Pfennig, ed., Phenotypic Plasticity and Evolution: Causes, Consequences, Controversies. CRC Press, Boca Raton, FL.

Crispo, E. 2007. The Baldwin effect and genetic assimilation: Revisiting two mechanisms of evolutionary change mediated by phenotypic plasticity. Evolution 61:2469-2479.

Danchin, É., A. Charmantier, F. A. Champagne, A. Mesoudi, B. Pujol, and S. Blanchet. 2011. Beyond DNA: Integrating inclusive inheritance into an extended theory of evolution. Nature Reviews Genetics 12:475-486.

Davies, N. B., J. R. Krebs, and S. A. West. 2012. An Introduction to Behavioural Ecology (4th edn.). Wiley-Blackwell, Oxford, UK.

Davison, D. R. and R. E. Michod. 2021. Phenotypic plasticity and evolutionary transitions in individuality. In D. W. Pfennig, ed. Phenotypic Plasticity and Evolution: Causes, Consequences, Controversies. CRC Press, Boca Raton, FL.

Day, T. and K. A. Young. 2004. Competitive and facilitative evolutionary diversification. BioScience 54:101-109.

de Jong, G. and P. Bijma. 2002. Selection and phenotypic plasticity in evolutionary biology and animal breeding. Livestock Production Science 78:195-214.

de la Serna Buzon, S., R. A. Martin, and D. W. Pfennig. 2020. Carryover effects and the evolution of polyphenism. Biological Journal of the Linnean Society 131:622-631.

Denver, R. J., N. Mirhadi, and M. Phillips. 1998. Adaptive plasticity in amphibian metamorphosis: Response of Scaphiopus hammondii tadpoles to habitat desiccation. Ecology 79:1859-1872.

DeWitt, T. J., A. Sih, and D. S. Wilson. 1998. Costs and limits of phenotypic plasticity. Trends In Ecology \& Evolution 13:1-8.

Diamond, S. E. and R. A. Martin. 2016. The interplay between plasticity and evolution in response to human-induced environmental change. F1000 Research 5:2835.

Diamond, S. E. and R. A. Martin. 2021. Buying time: Plasticity and population persistence. In D. W. Pfennig, ed., Phenotypic Plasticity and Evolution: Causes, Consequences, Controversies. CRC Press, Boca Raton, FL.

Dobzhansky, T. 1970. Genetics of the Evolutionary Process. Columbia University Press, New York, NY.

Dominguez-Salas, P., S. E. Moore, M. S. Baker, A. W. Bergen, S. E. Cox, R. A. Dyer, A. J. Fulford, Y. Guan, E. Laritsky, M. J. Silver, G. E. Swan, S. H. Zeisel, S. M. Innis, R. A. Waterland, A. M. Prentice, and B. J. Hennig. 2014. Maternal nutrition at conception modulates DNA methylation of human metastable epialleles. Nature Communications 5:3746. 
Ducatez, S., D. Sol, F. Sayol, and L. Lefebvre. 2020. Behavioural plasticity is associated with reduced extinction risk in birds. Nature Ecology \& Evolution. 4:788-793

Falconer, D. S. 1952. The problem of environment and selection. The American Naturalist 86:293-298.

Fitter, A. H. 2010. Anthony David Bradshaw. Biographical Memoirs of Fellows of the Royal Society 56:25-39.

Fordyce, J. A. 2006. The evolutionary consequences of ecological interactions mediated through phenotypic plasticity. Journal of Experimental Biology 209:2377-2383.

Fox, R. J., J. M. Donelson, C. Schunter, T. Ravasi, and J. D. Gaitán-Espitia. 2019. Beyond buying time: the role of plasticity in phenotypic adaptation to rapid environmental change. Philosophical Transactions of the Royal Society B-Biological Sciences 374:20180174.

Futuyma, D. J. 2021. How does phenotypic plasticity fit into evolutionary theory? In D. W. Pfennig, ed., Phenotypic Plasticity and Evolution: Causes, Consequences, Controversies. CRC Press, Boca Raton, FL.

Galloway, L. F. and J. R. Etterson. 2007. Transgenerational plasticity is adaptive in the wild. Science 318:1134-1136.

Galton, D. J. 2018. Standing on the Shoulders of Darwin and Mendel: Early Views of Inheritance. CRC Press, Boca Raton, FL.

Garland, T. and S. A. Kelly. 2006. Phenotypic plasticity and experimental evolution. Journal of Experimental Biology 209:2344-2361.

Ghalambor, C. K., J. K. McKay, S. Carroll, and D. N. Reznick. 2007. Adaptive versus nonadaptive phenotypic plasticity and the potential for contemporary adaptation to new environments. Functional Ecology 21:394-407.

Gibson, G. and I. Dworkin. 2004. Uncovering cryptic genetic variation. Nature Reviews Genetics 5:1199-1212.

Gilbert, S. F. and D. Epel. 2015. Ecological Developmental Biology: Integrating Epigenetics, Medicine, and Evolution. Sinauer, Sunderland, MA.

Gluckman, P. D., M. A. Hanson, P. Bateson, A. S. Beedle, C. M. Law, Z. A. Bhutta, K. V. Anokhin, P. Bougnères, G. R. Chandak, P. Dasgupta, G. D. Smith, P. T. Ellison, T. E. Forrester, S. F. Gilbert, E. Jablonka, H. Kaplan, A. M. Prentice, S. J. Simpson, R. Uauy, and M. J. West-Eberhard. 2009. Towards a new developmental synthesis: adaptive developmental plasticity and human disease. The Lancet 373:1654-1657.

Goldstein, I. and I. M. Ehrenreich. 2021. Genetic variation in phenotypic plasticity. In D. W. Pfennig, ed., Phenotypic Plasticity and Evolution: Causes, Consequences, Controversies. CRC Press, Boca Raton, FL.

Gomulkiewicz, R. and R. D. Holt. 1995. When does evolution by natural selection prevent extinction? Evolution 49:201-207.

Gottlieb, G. 1992. Individual Development and Evolution: The Genesis of Novel Behavior. Oxford University Press, New York.

Graham, L. 2016. Lysenko's Ghost: Epigenetics and Russia. Harvard University Press, Cambridge, MA.

Haldane, J. B. S. 1946. The interaction of nature and nurture. Annals of Eugenics 13:197-205.

Hendry, A. P. 2016. Key questions on the role of phenotypic plasticity in eco-evolutionary dynamics. Journal of Heredity 107:25-41.

Huey, R. B., P. E. Hertz, and B. Sinervo. 2003. Behavioral drive versus behavioral inertia in evolution: a null model approach. The American Naturalist 161:357-366.

Huxley, J. S. 1942 (2009). Evolution: The Modern Synthesis (with a new foreword by M. Pigliucci and G. B. Müller). MIT Press, Cambridge, MA.

IPCC. 2013. Climate Change 2013: The Physical Science Basis. Contribution of Working Group I to the Fifth Assessment Report of the Intergovernmental Panel on Climate Change. Cambridge University Press, Cambridge, United Kingdom and New York, NY, USA. 
Jones, P. A. 2012. Functions of DNA methylation: Islands, start sites, gene bodies and beyond. Nature Reviews Genetics 13:484-492.

Kamakura, M. 2011. Royalactin induces queen differentiation in honeybees. Nature 473:478-483.

Kawecki, T. J. 1994. Accumulation of deleterious mutations and the evolutionary cost of being a generalist. The American Naturalist 144:833-838.

Kishida, O. and K. Nishimura. 2004. Bulgy tadpoles: Inducible defense morph. Oecologia 140:414-421.

Kiss, J. Z. 2006. Up, down, and all around: how plants sense and respond to environmental stimuli. Proceedings of the National Academy of Sciences, U.S.A. 103:829-830.

Lafuente, E. and P. Beldade. 2019. Genomics of developmental plasticity in animals. Front Genet 10:720-720.

Laland, K. N., T. Uller, M. W. Feldman, K. Sterelny, G. B. Müller, A. P. Moczek, E. Jablonka, and F. J. Odling-Smee. 2014. Does evolutionary theory need a rethink? Yes, urgently. Nature 514:161-164.

Laland, K. N., T. Uller, M. W. Feldman, K. Sterelny, G. B. Müller, A. P. Moczek, E. Jablonka, and F. J. Odling-Smee. 2015. The extended evolutionary synthesis: Its structure, assumptions and predictions. Proceedings of the Royal Society B: Biological Sciences 282:20151019.

Ledón-Rettig, C. C., D. W. Pfennig, A. J. Chunco, and I. Dworkin. 2014. Cryptic genetic variation in natural populations: A predictive framework. Integrative and Comparative Biology 54:783-793.

Ledón-Rettig, C. C., D. W. Pfennig, and E. J. Crespi. 2010. Diet and hormone manipulations reveal cryptic genetic variation: Implications for the evolution of novel feeding strategies. Proceedings of the Royal Society B: Biological Sciences 277:3569-3578.

Ledón-Rettig, C. C., D. W. Pfennig, and N. Nascone-Yoder. 2008. Ancestral variation and the potential for genetic accommodation in larval amphibians: Implications for the evolution of novel feeding strategies. Evolution and Development 10:316-325.

Ledón-Rettig, C. C. and E. J. Ragsdale. 2021. Physiological mechanisms and the evolution of plasticity. In D. W. Pfennig, ed., Phenotypic Plasticity and Evolution: Causes, Consequences, Controversies. CRC Press, Boca Raton, FL.

Levene, H. 1953. Genetic equilibrium when more than one ecological niche is available. The American Naturalist 87:331-333.

Levins, R. 1968. Evolution in Changing Environments. Princeton University Press, Princeton, NJ.

Levis, N. A., A. Isdaner, and D. W. Pfennig. 2018. Morphological novelty emerges from preexisting phenotypic plasticity. Nature Ecology \& Evolution 2:1289-1297.

Levis, N. A. and D. W. Pfennig. 2016. Evaluating 'plasticity-first' evolution in nature: Key criteria and empirical approaches. Trends In Ecology \& Evolution 31:563-574.

Levis, N. A. and D. W. Pfennig. 2019. Plasticity-led evolution: Evaluating the key prediction of frequency-dependent adaptation. Proceedings of the Royal Society B 286:20182754.

Levis, N. A. and D. W. Pfennig. 2021. Innovation and diversification via plasticity-led evolution. In D. W. Pfennig, ed., Phenotypic Plasticity and Evolution: Causes, Consequences, Controversies. CRC Press, Boca Raton, FL.

Levis, N. A., E. M. X. Reed, D. W. Pfennig, and M. O. Buford Reiskind. 2020. Identification of candidate loci for adaptive phenotypic plasticity in natural populations of spadefoot toads. Ecology and Evolution 10:8976-8988.

Lewontin, R. C. 1974. The Genetic Basis of Evolutionary Change. Columbia University Press, New York.

Lister, A. M. 2021. Phenotypic plasticity in the fossil record. In D. W. Pfennig, ed., Phenotypic Plasticity and Evolution: Causes, Consequences, Controversies. CRC Press, Boca Raton, FL. 
Lyytinen, A., P. M. Brakefield, L. Lindström, and J. Mappes. 2004. Does predation maintain eyespot plasticity in Bicyclus anynana? Proceedings of the Royal Society B 271:279-283.

Maleszka, R. 2008. Epigenetic integration of environmental and genomic signals in honey bees: The critical interplay of nutritional, brain and reproductive networks. Epigenetics 3:188-192.

Martin, R. A. and D. W. Pfennig. 2009. Disruptive selection in natural populations: The roles of ecological specialization and resource competition. The American Naturalist 174:268-281.

Masel, J., O. D. King, and H. Maughan. 2007. The loss of adaptive plasticity during long periods of environmental stasis. The American Naturalist 169:38-46.

Matsuda, R. 1987. Animal Evolution in Changing Environments with Special Reference to Abnormal Metamorphosis. John Wiley and Sons, New York.

Mayr, E. 1963. Animal Species and Evolution. Harvard University Press, Cambridge, MA.

Mayr, E. 1985. Weismann and evolution. Journal of the History of Biology 18:295-329.

McCabe, J. and A. M. Dunn. 1997. Adaptive significance of environmental sex determination in an amphipod. Journal of Evolutionary Biology 10:515-527.

Meyers, L. A. and J. J. Bull. 2002. Fighting change with change: Adaptive variation in an uncertain world. Trends in Ecology and Evolution 17:551-557.

Michener, C. D. 1961. Social polymorphism in Hymenoptera. Symposium of the Royal Entomological Society of London 1:43-56.

Miller, M. B. and B. L. Bassler. 2001. Quorum sensing in bacteria. Annual Review of Microbiology 55:165-199.

Miryeganeh, M. and H. Saze. 2020. Epigenetic inheritance and plant evolution. Population Ecology 62:17-27.

Moczek, A. P. 1998. Horn polyphenism in the beetle Onthophagus taurus: Diet quality and plasticity in parental investment determine adult body size and male horn morphology. Behavioral Ecology 9:636-641.

Moczek, A. P. 2005. The evolution and development of novel traits, or how beetles got their horns. BioScience 11:935-951.

Moczek, A. P. and H. F. Nijhout. 2003. Rapid evolution of a polyphenic threshold. Evolution and Development 5:259-268.

Moczek, A. P., S. E. Sultan, S. Foster, C. Ledón-Rettig, I. Dworkin, H. F. Nijhout, E. Abouheif, and D. W. Pfennig. 2011. The role of developmental plasticity in evolutionary innovation. Proceedings of the Royal Society B: Biological Sciences 278:2705-2713.

Monaghan, P. 2008. Early growth conditions, phenotypic development and environmental change. Philosophical Transactions of the Royal Society B 363:1635-1645.

Mousseau, T. A. and C. W. Fox, eds. 1998. Maternal Effects as Adaptations. Oxford University Press, New York.

Murren, C. J., J. R. Auld, H. Callahan, C. K. Ghalambor, C. A. Handelsman, M. A. Heskel, J. G. Kingsolver, H. J. Maclean, J. Masel, H. Maughan, D. W. Pfennig, R. A. Relyea, S. Seiter, E. Snell-Rood, U. K. Steiner, and C. D. Schlichting. 2015. Constraints on the evolution of phenotypic plasticity: limits and costs of phenotype and plasticity. Heredity 115:293-301.

Murren, C. J., H. J. Maclean, S. E. Diamond, U. K. Steiner, M. A. Heskel, C. A. Handelsman, C. K. Ghalambor, J. R. Auld, H. S. Callahan, D. W. Pfennig, R. A. Relyea, C. D. Schlichting, and J. G. Kingsolver. 2014. Evolutionary change in continuous reaction norms. The American Naturalist 183:453-467.

Nettle, D. and M. Bateson. 2015. Adaptive developmental plasticity: What is it, how can we recognize it and when can it evolve? Proceedings of the Royal Society of London, Series B 282:20151005-20151005. 
Nijhout, H. F. 1994. Insect Hormones. Princeton University Press, Princeton, NJ.

Nijhout, H. F. 1999. Control mechanisms of polyphenic development in insects. BioScience 49:181-192.

Nijhout, H. F. 2003. Development and evolution of adaptive polyphenisms. Evolution and Development 5:9-18.

Noor, M. A. F., R. S. Parnell, and B. S. Grant. 2008. A reversible color polyphenism in American peppered moth (Biston betularia cognataria) caterpillars. PLOS ONE 3:e3142.

O'Brien, E. A., K. S. Ensbey, B. W. Day, P. A. Baldock, and G. Barry. 2020. Direct evidence for transport of RNA from the mouse brain to the germline and offspring. BMC Biology $18: 45$.

O'Donald, P. 1977. Frequency-dependence and polymorphism in models of sexual selection. The American Naturalist 111:195-196.

Oostra, V., M. Saastamoinen, B. J. Zwaan, and C. W. Wheat. 2018. Strong phenotypic plasticity limits potential for evolutionary responses to climate change. Nature Communications 9:1005.

Palacio-López, K., B. Beckage, S. Scheiner, and J. Molofsky. 2015. The ubiquity of phenotypic plasticity in plants: A synthesis. Ecology and Evolution 5:3389-3400.

Passera, L., E. Roncin, B. Kaufmann, and L. Keller. 1996. Increased soldier production in ant colonies exposed to intraspecific competition. Nature 379:630-631.

Pennisi, E. 2018. Buying time. Science 362:988-991.

Pfennig, D. W. 1990. The adaptive significance of an environmentally-cued developmental switch in an anuran tadpole. Oecologia 85:101-107.

Pfennig, D. W. and J. P. Collins. 1993. Kinship affects morphogenesis in cannibalistic salamanders. Nature 362:836-838.

Pfennig, D. W. and M. McGee. 2010. Resource polyphenism increases species richness: a test of the hypothesis. Philosophical Transactions of the Royal Society of London, Series B 365:577-591.

Pfennig, D. W. and K. S. Pfennig. 2012. Evolution's Wedge: Competition and the Origins of Diversity. University of California Press, Berkeley, CA.

Pfennig, D. W. and P. W. Sherman. 1995. Kin recognition. Scientific American 272:98-103.

Pfennig, D. W., P. W. Sherman, and J. P. Collins. 1994. Kin recognition and cannibalism in polyphenic salamanders. Behavioral Ecology 5:225-232.

Pfennig, D. W., M. A. Wund, E. C. Snell-Rood, T. Cruickshank, C. D. Schlichting, and A. P. Moczek. 2010. Phenotypic plasticity's impacts on diversification and speciation. Trends in Ecology and Evolution 25: 459-467.

Pienaar, J. and J. M. Greeff. 2003. Different male morphs of Otitesella pseudoserrata fig wasps have equal fitness but are not determined by different alleles. Ecology Letters 6:286-289.

Pigliucci, M. 2007. Do we need an extended evolutionary synthesis? Evolution 61:2743-2749.

Pigliucci, M. and L. Finkelman. 2014. The extended (evolutionary) synthesis debate: Where science meets philosophy. BioScience 64:511-516.

Ptashne, M. 2004. A Genetic Switch: Phage Lambda Revisited. Cold Springs Harbor Laboratory Press, Cold Springs Harbor, NY.

Reeve, H. K. 1989. The evolution of conspecific acceptance thresholds. The American Naturalist 133:407-435.

Relyea, R. 2004. Fine-tuned phenotypes: Tadpole plasticity under 16 combinations of predators and competitors. Ecology 85:172-179.

Reznick, D. N., J. Losos, and J. Travis. 2019. From low to high gear: There has been a paradigm shift in our understanding of evolution. Ecology Letters 22:233-244.

Robertson, A. 1977. Conrad Hal Waddington. Biographical Memoirs of Fellows of the Royal Society 23:575-622.

Robinson, B. W. and R. Dukas. 1999. The influence of phenotypic modifications on evolution: The Baldwin effect and modern perspectives. Oikos 85:582-589. 
Rueffler, C., T. J. M. Van Dooren, O. Leimar, and P. A. Abrams. 2006. Disruptive selection and then what? Trends in Ecology and Evolution 21:238-245.

Sakar, S. 1999. From the Reaktionsnorm to the adaptive norm: The norm of reaction 19091960. Biology and Philosophy 14:235-252.

Scheiner, S. M. 2014. The Baldwin Effect: Neglected and misunderstood. The American Naturalist 184:ii-iii.

Scheiner, S. M. 2020. The theory of the evolution of plasticity, pp. 254-272. In S. M. Scheiner, and D. P. Mindell, eds., The Theory of Evolution. University of Chicago Press, Chicago.

Scheiner, S. M., M. Barfield, and R. D. Holt. 2017. The genetics of phenotypic plasticity. XV. Genetic assimilation, the Baldwin effect, and evolutionary rescue. Ecology and Evolution 7:8788-8803.

Scheiner, S. M. and N. A. Levis. 2021. The loss of phenotypic plasticity via natural selection: Genetic assimilation. In D. W. Pfennig, ed., Phenotypic Plasticity and Evolution: Causes, Consequences, Controversies. CRC Press, Boca Raton, FL.

Schlichting, C. D. 2021. Plasticity and evolutionary theory: Where we are and where we should be going. In D. W. Pfennig, ed., Phenotypic Plasticity and Evolution: Causes, Consequences, Controversies. CRC Press, Boca Raton, FL.

Schmalhausen, I. I. 1949 (1986). Factors of Evolution: The Theory of Stabilizing Selection. University of Chicago Press, Chicago.

Schneider, R. F. and A. Meyer. 2017. How plasticity, genetic assimilation and cryptic genetic variation may contribute to adaptive radiations. Molecular Ecology 26:330-350.

Schwander, T. and O. Leimar. 2011. Genes as leaders and followers in evolution. Trends In Ecology and Evolution 26:143-151.

Shapiro, A. M. 1976. Seasonal polyphenism, pp. 259-333. In M. K. Hecht, W. C. Steere, and B. Wallace, eds., Evolutionary Biology, Volume 9. Springer US, Boston, MA.

Shaw, C. A., J. C. McEachern, and J. McEachern, eds., 2001. Toward a Theory of Neuroplasticity. Psychology Press, London.

Simpson, G. G. 1953. The Baldwin effect. Evolution 7:110-117.

Sinervo, B. and R. Calsbeek. 2006. The developmental, physiological, neural, and genetical causes and consequences of frequency-dependent selection in the wild. Annual Review of Ecology, Evolution, and Systematics 37:581-610.

Sinervo, B. and C. M. Lively. 1996. The rock-scissors-paper game and the evolution of alternative male strategies. Nature 340:240-246.

Snell-Rood, E. C. and S. Ehlman. 2021. Ecology and evolution of plasticity. In D. W. Pfennig, ed., Phenotypic Plasticity and Evolution: Causes, Consequences, Controversies. CRC Press, Boca Raton, FL.

Snell-Rood, E. C., M. E. Kobiela, K. L. Sikkink, and A. M. Shephard. 2018. Mechanisms of plastic rescue in novel environments. Annual Review of Ecology, Evolution, and Systematics 49:331-354.

Snell-Rood, E. C., J. D. Van Dyken, T. Cruickshank, M. J. Wade, and A. P. Moczek. 2010. Toward a population genetic framework of developmental evolution: The costs, limits, and consequences of phenotypic plasticity. Bioessays 32:71-81.

Stabell, O. B., F. Ogbeto, and R. Primicerio. 2003. Inducible defenses in Daphnia depend on latent signals from conspecific prey activated in predators. Chemical Senses 28:141-153.

Stevens, M. 2013. Sensory Ecology, Behaviour, and Evolution. Oxford University Press, Oxford, UK.

Sultan, S. E. 2015. Organisms and Environment: Ecological Development, Niche Construction, and Adaptation. Oxford University Press, Oxford, UK.

Sultan, S. E. 2021. Phenotypic plasticity as an intrinsic property of organisms. In D. W. Pfennig, ed., Phenotypic Plasticity and Evolution: Causes, Consequences, Controversies. CRC Press, Boca Raton, FL. 
Suzuki, Y. and H. F. Nijhout. 2006. Evolution of a polyphenism by genetic accommodation. Science 311:650-652.

Thackeray, S. J., P. A. Henrys, D. Hemming, J. R. Bell, M. S. Botham, S. Burthe, P. Helaouet, D. G. Johns, I. D. Jones, D. I. Leech, E. B. Mackay, D. Massimino, S. Atkinson, P. J. Bacon, T. M. Brereton, L. Carvalho, T. H. Clutton-Brock, C. Duck, M. Edwards, J. M. Elliott, S. J. G. Hall, R. Harrington, J. W. Pearce-Higgins, T. T. Høye, L. E. B. Kruuk, J. M. Pemberton, T. H. Sparks, P. M. Thompson, I. White, I. J. Winfield, and S. Wanless. 2016. Phenological sensitivity to climate across taxa and trophic levels. Nature 535:241-245.

U. S. National Institutes of Health. 2020. Genetics Home Reference webpage. https://ghr.nlm. nih.gov/primer/hgp/genome (accessed July 18, 2020).

Van Buskirk, J., S. A. McCollum, and E. E. Werner. 1997. Natural selection for environmentally induced phenotypes in tadpoles. Evolution 51:1983-1992.

Van Dyken, J. D. and M. J. Wade. 2010. The genetic signature of conditional expression. Genetics 184:557-570.

Waddington, C. H. 1942. Canalization of development and the inheritance of acquired characters. Nature 150:563-565.

Waddington, C. H. 1953. Genetic assimilation of an acquired character. Evolution 7:118-126.

Wang, Y., H. Liu, and Z. Sun. 2017. Lamarck rises from his grave: Parental environmentinduced epigenetic inheritance in model organisms and humans. Biological Reviews 92:2084-2111.

War, A. R., M. G. Paulraj, T. Ahmad, A. A. Buhroo, B. Hussain, S. Ignacimuthu, and H. C. Sharma. 2012. Mechanisms of plant defense against insect herbivores. Plant Signal Behav 7:1306-1320.

Warkentin, K. M. 1995. Adaptive plasticity in hatching age: A response to predation risk trade-offs. Proceedings of the National Academy of Sciences of the United States of America 92:3507-3510.

Watt, W. B. 1968. Adaptive significance of pigment polymorphism in Colias butterflies. I. Variation in melanin in relation to thermoregulation. Evolution 22:437-458.

Webber, B. H. and D. J. Depew. 2003. Evolution and Learning: The Baldwin Effect Reconsidered. MIT Press, Cambridge, MA.

Weber, C., Y. Zhou, J. G. Lee, L. L. Looger, G. Qian, C. Ge, and B. Capel. 2020. Temperaturedependent sex determination is mediated by pSTAT3 repression of Kdm6b. Science 368:303-306.

Wells, C. L. and M. Pigliucci. 2000. Adaptive phenotypic plasticity: The case of heterophylly in aquatic plants. Perspectives in Plant Ecology, Evolution and Systematics $3: 1-18$.

West-Eberhard, M. J. 1989. Phenotypic plasticity and the origins of diversity. Annual Review of Ecology, Evolution, and Systematics 20:249-278.

West-Eberhard, M. J. 2003. Developmental Plasticity and Evolution. Oxford University Press, New York.

West-Eberhard, M. J. 2019. Nutrition, the visceral immune system, and the evolutionary origins of pathogenic obesity. Proceedings of the National Academy of Sciences 116:723-731.

West-Eberhard, M. J. 2021. Foreword: A perspective on 'plasticity'. In D. W. Pfennig, ed., Phenotypic Plasticity and Evolution: Causes, Consequences, Controversies. CRC Press, Boca Raton, FL

Wheeler, D. E. 1986. Developmental and physiological determinants of caste in social Hymenoptera: Evolutionary implications. The American Naturalist 128:13-34.

Whitlock, M. C. 1996. The red queen beats the jack-of-all-trades: The limitations on the evolution of phenotypic plasticity and niche breadth. The American Naturalist 148:S65-S77. 
Whitman, D. W. and A. A. Agrawal. 2009. What is phenotypic plasticity and why is it important? pp. 1-63. In D. W. Whitman, and T. N. Ananthakrishnan, eds. Phenotypic Plasticity of Insects. Science Publishers, Enfield, NH.

Wiley, R. H. 2015. Noise Matters: The Evolution of Communication. Harvard University Press, Cambridge, MA.

Wilson, E. O. 1971. The Insect Societies. Belknap Press, Cambridge, MA.

Winther, R. G. 2001. August Weismann on germ-plasm variation. Journal of the History of Biology 34:517-555.

Wright, S. 1931. Evolution in Mendelian populations. Genetics 16:97-159.

Wund, M. A. 2012. Assessing the impacts of phenotypic plasticity on evolution. Integrative and Comparative Biology 52:5-15.

Wund, M. A., J. A. Baker, B. Clancy, J. L. Golub, and S. A. Foster. 2008. A test of the "flexible stem" model of evolution: Ancestral plasticity, genetic accommodation, and morphological divergence in the threespine stickleback radiation. The American Naturalist 172:449-462.

Zirkle, C. 1946. The early history of the idea of the inheritance of acquired characters and of pangenesis. Transactions of the American Philosophical Society 35:91-151. 